\title{
Parameterizing cloud condensation nuclei concentrations during HOPE
}

\author{
Luke B. Hande ${ }^{1}$, Christa Engler ${ }^{2}$, Corinna Hoose ${ }^{1}$, and Ina Tegen ${ }^{2}$ \\ ${ }^{1}$ Karlsruhe Institute of Technology, Karlsruhe, Germany \\ ${ }^{2}$ Leibniz-Institute for Tropospheric Research, Leipzig, Germany \\ Correspondence to: Luke B. Hande (luke.hande@kit.edu)
}

Received: 26 April 2016 - Published in Atmos. Chem. Phys. Discuss.: 4 May 2016

Revised: 9 August 2016 - Accepted: 6 September 2016 - Published: 27 September 2016

\begin{abstract}
An aerosol model was used to simulate the generation and transport of aerosols over Germany during the $\mathrm{HD}(\mathrm{CP})^{2}$ Observational Prototype Experiment (HOPE) field campaign of 2013. The aerosol number concentrations and size distributions were evaluated against observations, which shows satisfactory agreement in the magnitude and temporal variability of the main aerosol contributors to cloud condensation nuclei $(\mathrm{CCN})$ concentrations. From the modelled aerosol number concentrations, number concentrations of CCN were calculated as a function of vertical velocity using a comprehensive aerosol activation scheme which takes into account the influence of aerosol chemical and physical properties on CCN formation. There is a large amount of spatial variability in aerosol concentrations; however the resulting CCN concentrations vary significantly less over the domain. Temporal variability is large in both aerosols and $\mathrm{CCN}$. A parameterization of the $\mathrm{CCN}$ number concentrations is developed for use in models. The technique involves defining a number of best fit functions to capture the dependence of CCN on vertical velocity at different pressure levels. In this way, aerosol chemical and physical properties as well as thermodynamic conditions are taken into account in the new CCN parameterization. A comparison between the parameterization and the $\mathrm{CCN}$ estimates from the model data shows excellent agreement. This parameterization may be used in other regions and time periods with a similar aerosol load; furthermore, the technique demonstrated here may be employed in regions dominated by different aerosol species.
\end{abstract}

\section{Introduction}

The influence that aerosols have on cloud microphysics is relatively well established; however clouds and aerosols continue to contribute the largest uncertainty to the Earth's energy budget in climate simulations (Boucher et al., 2013). In an effort to realistically capture aerosol cloud interactions and hence reduce these uncertainties, cloud condensation nuclei $(\mathrm{CCN})$ parameterizations have been developed for models. The ability of an aerosol to act as a CCN is determined by its size and composition, so accurately modelling $\mathrm{CCN}$ activation necessitates an understanding of these underlying physical and chemical properties.

The hygroscopicity parameter is now commonly used to characterize the chemical properties of a given aerosol species (Petters and Kreidenweis, 2007); however for the sake of simplicity, chemical composition can be neglected. Segal and Khain (2006) state that aerosol chemical composition has a relatively small effect and assume all aerosols are composed of $\mathrm{NaCl}$. Some doubt does remain as to the relative importance of the aerosol physical and chemical properties in determining CCN concentrations (Hudson, 2007); however most evidence suggests that number concentration and size have the most significant effect (Dusek et al., 2006; Ervens et al., 2007; Feingold, 2003), since larger particles are more readily activated.

There are numerous possibilities for characterizing the number concentration of aerosols. Early parameterizations, including the seminal work of Twomey (1959), used a power law to describe the number of activated CCN. A power law can also be employed to describe the aerosol population; however this approach combined with simple expressions for 
the number of nucleated drops has drawbacks, since anomalously high droplet number concentrations can be produced. A power law is also employed to define the aerosol size distribution (Khvorostyanov and Curry, 1999) in parameterizations of droplet activation (Morrison et al., 2005) employed by the Weather Research and Forecasting (WRF) model.

Other parameterizations assume a prescribed uniform aerosol size distribution with only one typically log-normal mode (Abdul-Razzak et al., 1998; Segal and Khain, 2006). Several modes can be used to define the aerosol sizes (AbdulRazzak and Ghan, 2000; Fountoukis and Nenes, 2005; Liu et al., 2012; Shipway and Abel, 2010), where the parameters of the size distribution are either calculated from an aerosol model or derived from limited observations from a short time period (Rissler et al., 2004). If coupled to another suitable model, e.g. the CAM-Oslo GCM, the aerosol modes can evolve over time, offering the next degree of complexity. Parameterizations can also employ a sectional representation of the aerosol size distribution (Abdul-Razzak and Ghan, 2002; Nenes and Seinfeld, 2003), which also allows the size distribution to evolve over time.

Perhaps unsurprisingly, a more complex representation of aerosol properties and processes leads to improvements in simulated aerosol forcing (Bellouin et al., 2013; Mann et al., 2012), as well as CCN concentrations (Weisenstein et al., 2007). However these approaches introduce a significant computational burden for simulations, which limits their applicability to short, limited-area simulations.

Segal and Khain (2006) point out that an effective parameterization should be as simple as possible, yet encompass all the governing factors affecting aerosol activation. This sentiment has also been echoed by Petters and Kreidenweis (2007). To this end, we present a parameterization for estimating $\mathrm{CCN}$ concentrations which exploits the complexity of an aerosol model to accurately characterize chemical and physical properties of aerosols. All these detailed properties are then represented within a simple mathematical model, which is a function of the vertical velocity and atmospheric pressure. This represents a new approach for parameterizing $\mathrm{CCN}$ for use in models. The parameterization is developed for use in the large eddy simulation (LES) version of the ICOsahedral Nonhydrostatic (ICON) model, from modelled aerosol data during the $\mathrm{HD}(\mathrm{CP})^{2}$ Observational Prototype Experiment (HOPE) campaign. It is suggested the parameterization is suitable for other time periods with a similar aerosol load.

\section{Aerosol simulations}

The High Definition Clouds and Precipitation for advancing Climate Prediction $\left(\mathrm{HD}(\mathrm{CP})^{2}\right)$ project aims at improving our understanding of clouds and precipitation, by building and using a model capable of very high-resolution simulations. An essential component of this project is the use of the ICON
Table 1. Aerosol physical and chemical properties.

\begin{tabular}{lrrrr}
\hline Species & $\kappa$ & $\sigma(\mu \mathrm{m})$ & $r(\mu \mathrm{m})$ & $\rho\left(\mathrm{kg} \mathrm{m}^{-3}\right)$ \\
\hline Amm nitrate & 0.54 & 1.6 & 0.05 & 1.725 \\
Amm sulfate & 0.51 & 1.6 & 0.05 & 1.77 \\
Dust 1 & 0.14 & 2.0 & 0.2 & 2.65 \\
Dust 2 & 0.14 & 2.0 & 0.6 & 2.65 \\
Dust 3 & 0.14 & 2.0 & 1.75 & 2.65 \\
Dust 4 & 0.14 & 2.0 & 5.25 & 2.65 \\
Dust 5 & 0.14 & 2.0 & 15.95 & 2.65 \\
Elemental C & $5 \times 10^{-7}$ & 1.8 & 0.03 & 1.8 \\
Organic C & 0.14 & 1.8 & 0.055 & 1.0 \\
Sea salt 1 & 1.16 & 1.8 & 0.065 & 2.2 \\
Sea salt 2 & 1.16 & 1.7 & 0.645 & 2.2 \\
Sulfate & 0.236 & 1.6 & 0.05 & 1.8 \\
\hline
\end{tabular}

model to preform large eddy simulations, as demonstrated by Dipankar et al. (2015). The ICON-LES model has no online aerosol scheme, which motivates the need for the new $\mathrm{CCN}$ parameterization developed here. To achieve this, the Consortium for Small-scale Modelling (COSMO) meteorological model coupled to the Multi-Scale Chemistry Aerosol Transport (MUSCAT) (Wolke et al., 2012) model was used to simulate the generation and transport of natural and anthropogenic aerosols to Europe. The time period covers the $\mathrm{HD}(\mathrm{CP})^{2}$ Observational Prototype Experiment (HOPE) performed in Jülich, Germany, which will provide critical data for model evaluation.

The aerosol species simulated were ammonium nitrate, ammonium sulfate, dust (5 sizes), elemental carbon, organic carbon, sea salt ( 2 sizes), and sulfate. Table 1 shows the chemical and physical properties of the simulated aerosols. The hygroscopicity parameter is $\kappa$, the mode standard deviation and mean radius are $\sigma$ and $r$ respectively, and the density is given by $\rho$. The hygroscopicity parameter for each aerosol species was taken from Ghan et al. (2001).

In COSMO-MUSCAT, the meteorological model COSMO, which is the operational forecast model of the German Weather Service (DWD), is coupled online with the chemistry transport model MUSCAT. Meteorological parameters such as humidity and temperature are interpolated and transferred from COSMO-MUSCAT at each advection time step. This ensures that actual meteorological conditions are represented. MUSCAT computes atmospheric transport and chemical transformations of aerosol species and gas phase reactions. The transport processes include advection, turbulent diffusion, sedimentation, and dry and wet deposition. In addition, size-resolved atmospheric particle number concentrations were simulated for Saharan dust aerosol. While the number distribution of secondary aerosol species are particularly important for determining cloud condensation nuclei concentrations, dust particles are efficient ice nuclei. 


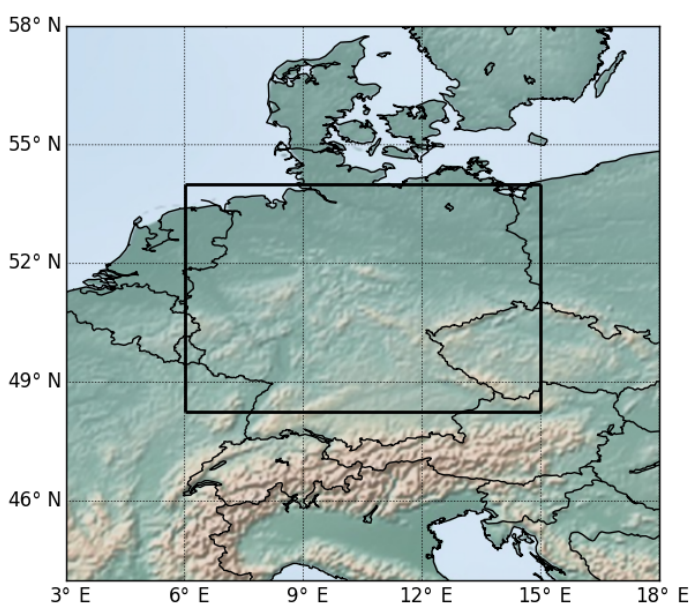

Figure 1. Domain over Germany used in this study.

For the model results shown here, the horizontal grid spacing was $28 \mathrm{~km}$, and 32 vertical layers were used. The domain considered in this study is between $48.25-54^{\circ} \mathrm{N}$ and $6-15^{\circ} \mathrm{E}$, shown in Fig. 1. To ensure that the deviations in the modelled meteorological fields from the real atmosphere remain small, COSMO was reinitialized every $24 \mathrm{~h}$. COSMO ran for $48 \mathrm{~h}$ at each cycle, and after $24 \mathrm{~h}$ MUSCAT was restarted. Then, both models ran parallel for $24 \mathrm{~h}$ at each cycle. For the chemical compounds and aerosol species, MUSCAT computes total mass concentration. The model has been applied and tested for numerous case studies in Germany as well as in annual simulations in the European domain (Wolke et al., 2012).

For the estimation of the aerosol number size distributions, the mode mean diameter, density, and standard deviation of the log-normal mode have been predefined for each aerosol species. Dust size distributions have been described by Heinold et al. (2011). Sea salt modes are determined according to Gong (2003). The simulated mass concentrations were converted to total number concentrations by assuming spherical particles of a certain size and density individually for each component. Assuming a log-normal size distribution with a certain mean diameter and standard deviation, the total number concentration can then be used to estimate the number size distribution for each component. The sum of all individual size distributions results in the total particle size distribution, which can be compared to the observations.

The aerosol mixing state can influence aerosol size distribution and hygroscopicity, hence it influences CCN activity. Wang et al. (2010) shows that mixing state assumption is only important when primary organic aerosol and black carbon dominate aerosol volume. Here, aerosol composition is mostly from ammonium nitrate and ammonium sulfate. Sullivan et al. (2009) show that not all chemical reactions that process atmospheric dust aerosols increase $\mathrm{CCN}$ activity. Therefore mixing state assumption should not affect the results strongly. Furthermore, Ervens et al. (2010) show that simple mixing state assumptions are insufficient only very close to the pollution sources.

\section{Aerosol measurements and simulation evaluation}

Model simulations were performed for the period 26 March to 20 June 2013, which covers the period of the HOPE field campaign in Jülich. Furthermore, the model was evaluated for the site Melpitz near Leipzig ( $87 \mathrm{~m}$ a.s.1.; $51.53^{\circ} \mathrm{N}$; $12.90^{\circ}$ E) (Engler et al., 2007; Spindler et al., 2013), since no specific aerosol measurements were carried out during the campaign at the Jülich site. Therefore, comparisons of modelled and observed aerosol composition size distributions were performed at the Melpitz site. The station is situated on flat terrain, and no larger sources of pollution lie within close proximity to the station. Particle number size distributions at dry conditions were measured using a twin differential mobility particle sizer (TDMPS) (Birmili et al., 1999, 2016). The major ions and carbon species in the aerosol have been continuously measured from daily filter samples since 2003 (Spindler et al., 2013).

A comparison of modelled and observed chemical species is shown in Fig. 2 for the time period of the HOPE Melpitz campaign. Only the results of modelled and observed concentrations of the species ammonium sulfate and ammonium nitrate as well as the small sea salt mode are shown, as these species dominate $\mathrm{CCN}$ concentrations over the model domain. The agreement between the model results and observations of the mass concentrations of secondary aerosol species as well as the sea salt is very good. Both magnitude and temporal variability of the aerosol concentrations are well matched except for the first few days of the time period, where the model underestimates the observed aerosol species, particularly for ammonium nitrate and to a lesser extent for ammonium sulfate and sea salt. Total $\mathrm{PM}_{2.5}$, which is computed as the sum of all aerosol types excluding the supermicron size dust and sea salt fractions, is underestimated by the model by about a factor of 2 . This underestimate can likely be tied to an underestimated submicron dust emission or secondary organic aerosol (SOA) that is not considered by the model. Zhao et al. (2015) suggest SOAs have hygroscopicity parameters between 0.03 and 0.1 , less than the majority of aerosols considered in this study. Therefore, any underestimate in SOA concentration should not affect $\mathrm{CCN}$ concentrations significantly.

The modelled aerosol size distribution resulting from conversion of the simulated bulk aerosol concentration into sizeresolved aerosol concentration at the Jülich site is shown in Fig. 3 for the example day 18 June 2013 at 12:00 UTC. Here, ammonium sulfate contributes the main part to the modelled aerosol number concentrations. These results could not be verified at the Jülich site due to lack of observations. There- 

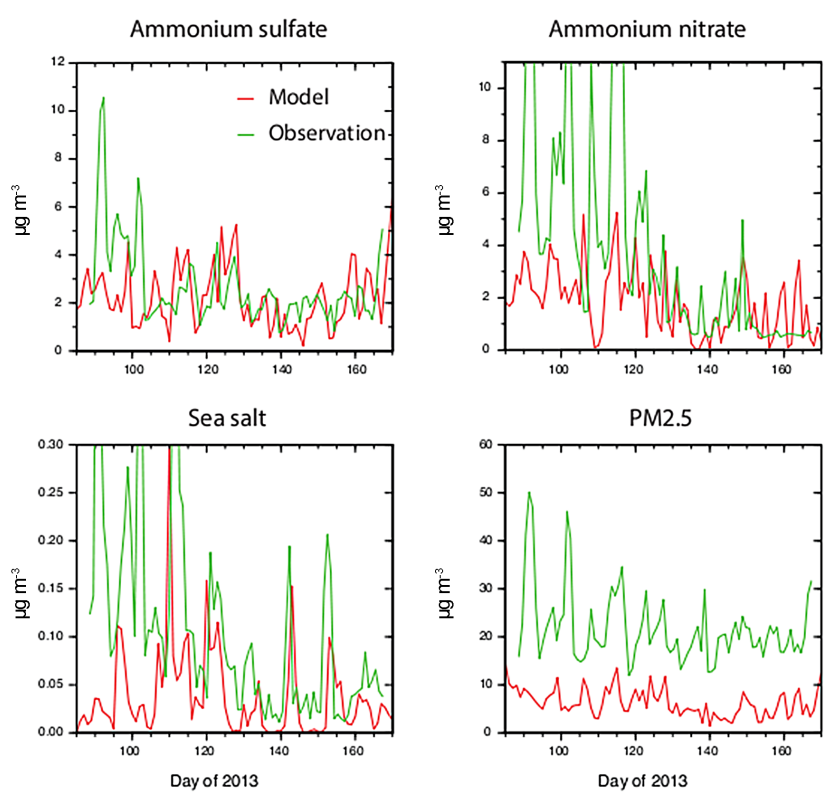

Figure 2. Comparison of the modelled and observed concentrations of aerosol species ammonium sulfate, ammonium nitrate, sea salt, and total $\mathrm{PM}_{2.5}$ at the Melpitz site for the HOPE simulation period in spring 2013.

fore, comparisons of modelled and observed size distributions were performed at the Melpitz site (Fig. 3b).

While in the size range between $50 \mathrm{~nm}$ and $0.15 \mu \mathrm{m}$ the model estimated number size distribution matches the observations well, the model underestimates the observations at smaller and larger particle sizes. This is also the case when comparing model results and observations for a full month (Fig. 3c). For particles between about 10 and $30 \mathrm{~nm}$, the model underestimates the number concentration by 12 orders of magnitude for the whole month. A smaller discrepancy is seen for course mode aerosols, where the model suggests about half the concentrations given in the observations for $0.5 \mu \mathrm{m}$ particles. The underestimation at smaller sizes is due to the fact that the nucleation mode, which is present in the measurements, is not taken into account in the model. However, at this size range such an underestimate is less important for diagnosing CCN concentrations. The underestimate of the model results at larger particle sizes (also reflected in underestimates of $\mathrm{PM}_{2.5}$ and $\mathrm{PM}_{10}$ concentrations, not shown) may be more critical; however the number concentrations of the large particles are low. The model deficit may point to an aerosol type that is not included in the model, for example fugitive dust. Natural sea salt and desert dust aerosol are unlikely to be responsible for this deficit at the larger particle sizes, since the sea salt large mode was adjusted to observations, while independent comparisons of dust aerosol size distributions with observations during measurements at independent field campaigns have shown that simulated dust size distributions in the supermi-
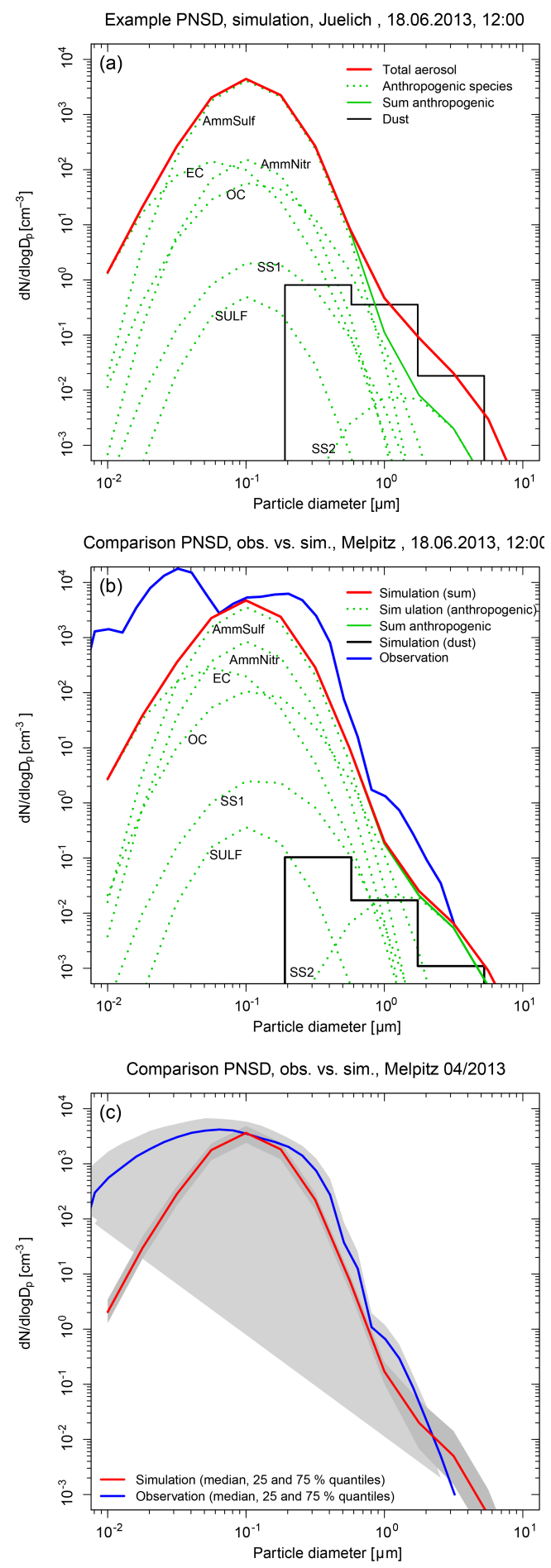

Figure 3. Aerosol particle number size distribution for 18 June 2013 at the sites Jülich (a) and Melpitz (b), and for the month April 2013 at Melpitz (c). The red lines mark the resulting simulated aerosol size distributions for the sum of the individual species (dotted green lines). Black lines represent modelled number size distribution of dust transported from the Sahara desert to the sites Jülich and Melpitz respectively. 

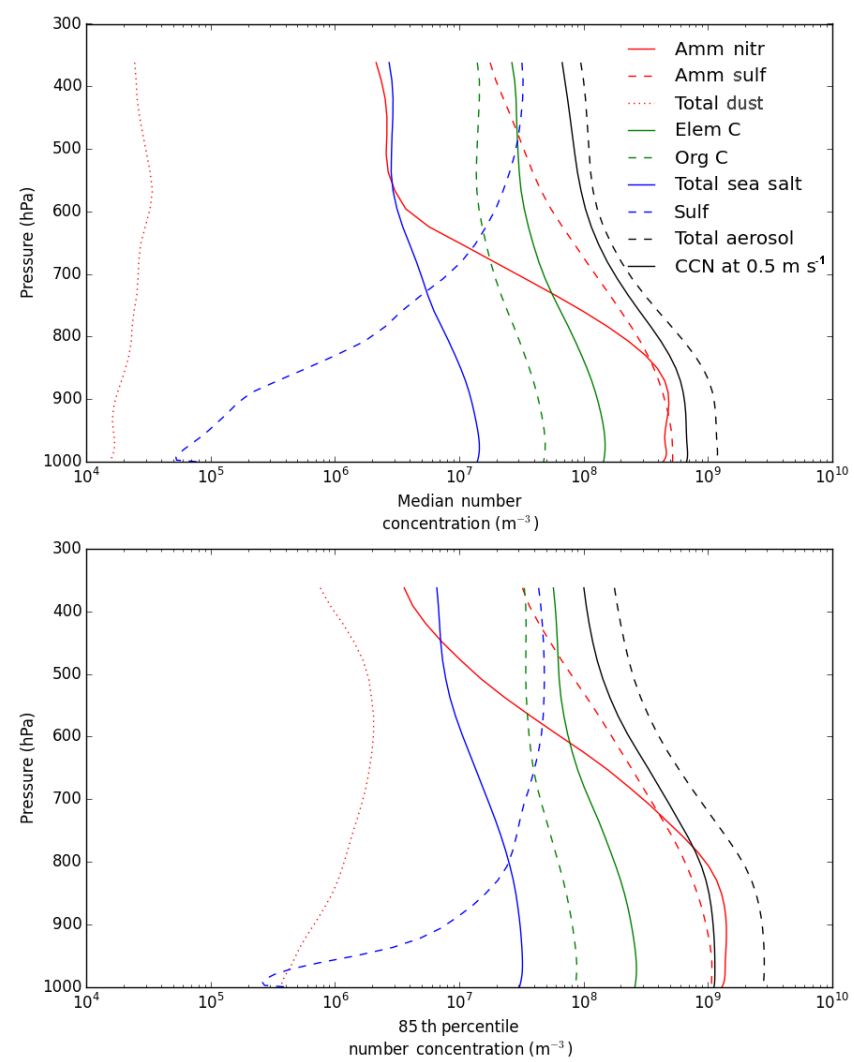

Figure 4. Temporally averaged median (top) and 85th percentile (bottom) number concentration for aerosols and $\mathrm{CCN}$ at $0.5 \mathrm{~m} \mathrm{~s}^{-1}$ from 25 March to 16 June 2013.

cron size range match well to ground and airborne dust size observations (Heinold et al., 2011).

\section{Aerosol and CCN concentrations during HOPE}

Figure 4 shows the temporally averaged median and 85 th percentile vertical profiles of the number concentration of all aerosol species and the resulting $\mathrm{CCN}$ number concentration at a prescribed vertical velocity of $0.5 \mathrm{~m} \mathrm{~s}^{-1}$. To calculate the statistics, the domain-wide median and 85 th percentile vertical profiles were first calculated at each time step. Then the mean of these profiles was taken over all time steps.

According to Fig. 4, the dominant aerosols in the lower levels are ammonium nitrate and ammonium sulfate, and at higher levels the concentration of sulfate and elemental carbon become more significant. The concentrations of most aerosol species are constant at lower levels, and decrease at higher levels, with the rate of decrease varying between aerosol species. Sulfate is the exception, with concentrations increasing with altitude due to the nucleation of Aitken mode particles in the upper troposphere. In the model, sulfate is formed by the oxidation of $\mathrm{SO}_{2}$, which instantly reacts to form ammonium sulfate if ammonium is available (Renner and Wolke, 2010). In the upper troposphere, less ammonium is available, which leads to the nucleation of sulfate particles. The median dust concentrations are relatively constant with altitude, as already shown by Hande et al. (2015) during a different time period.

The bottom panel of Fig. 4 shows the temporally averaged 85th percentile concentrations of aerosols and $\mathrm{CCN}$ at $0.5 \mathrm{~m} \mathrm{~s}^{-1}$. Taking the ratio of the 85 th percentile concentrations to the median concentrations provides a rough measure of the spatial variability. For example, the 85th percentile for ammonium nitrate is, on average, 5.6 times larger than the median. This increases to 44 times larger for dust, with the smallest difference being 2.1 times for organic carbon. In contrast to this, the 85th percentile for $\mathrm{CCN}$ concentrations is only 1.8 times larger than the median concentrations on average. This indicates that, while there may be significant spatial variability in aerosol concentrations, the spatial variability in $\mathrm{CCN}$ concentrations is significantly lower.

The spatial variability on shorter timescales, as well as the temporal variability over the course of the HOPE campaign are shown in Fig. 5. The latitudinal and longitudinal median aerosol number concentrations and the resulting $\mathrm{CCN}$ number concentrations, averaged over all pressure levels and time steps for 1 day, 30 April 2013, are shown in the top and middle panel, and the bottom panel shows the temporal variability. For this specific day, ammonium nitrate shows a significant amount of variability in both latitude and longitude. Sea salt aerosols also have a large amount of variability with a strong north-south gradient, consistent with the source region being the oceans north of Germany. Indeed, north of the domain, sea salt becomes the dominant aerosol. The important point is that, while there may be large variability in the spatial distribution of aerosols, the spatial variability in the resulting $\mathrm{CCN}$ is significantly lower. Even when individual pressure levels are considered, spatial variability in CCN concentrations remains low. The largest variability is in the north-west of the domain above $400 \mathrm{hPa}$, where concentrations are up to 7 times higher than the rest of the domain. $\mathrm{CCN}$ concentrations at $400 \mathrm{hPa}$ are more than 2 orders of magnitude lower than near the surface; therefore the impact of this error is small.

The same conclusion regarding the horizontal homogeneity of $\mathrm{CCN}$ number concentrations over Germany can be obtained from analysing other days across the whole campaign time period. The spatial distribution of the aerosols can change significantly, particularly for ammonium nitrate, dust, and sea salt. This is consistent with the findings from analysing the difference between the 85 th percentile and the median concentrations, as done above. However the resulting $\mathrm{CCN}$ number concentrations are much more homogeneous over the domain. Concentrations typically vary by around a factor of 2 over the domain. The temporal variability over the whole time period, on the other hand, is larger, as shown in the bottom panel of Fig. 5. However, if shorter time periods 

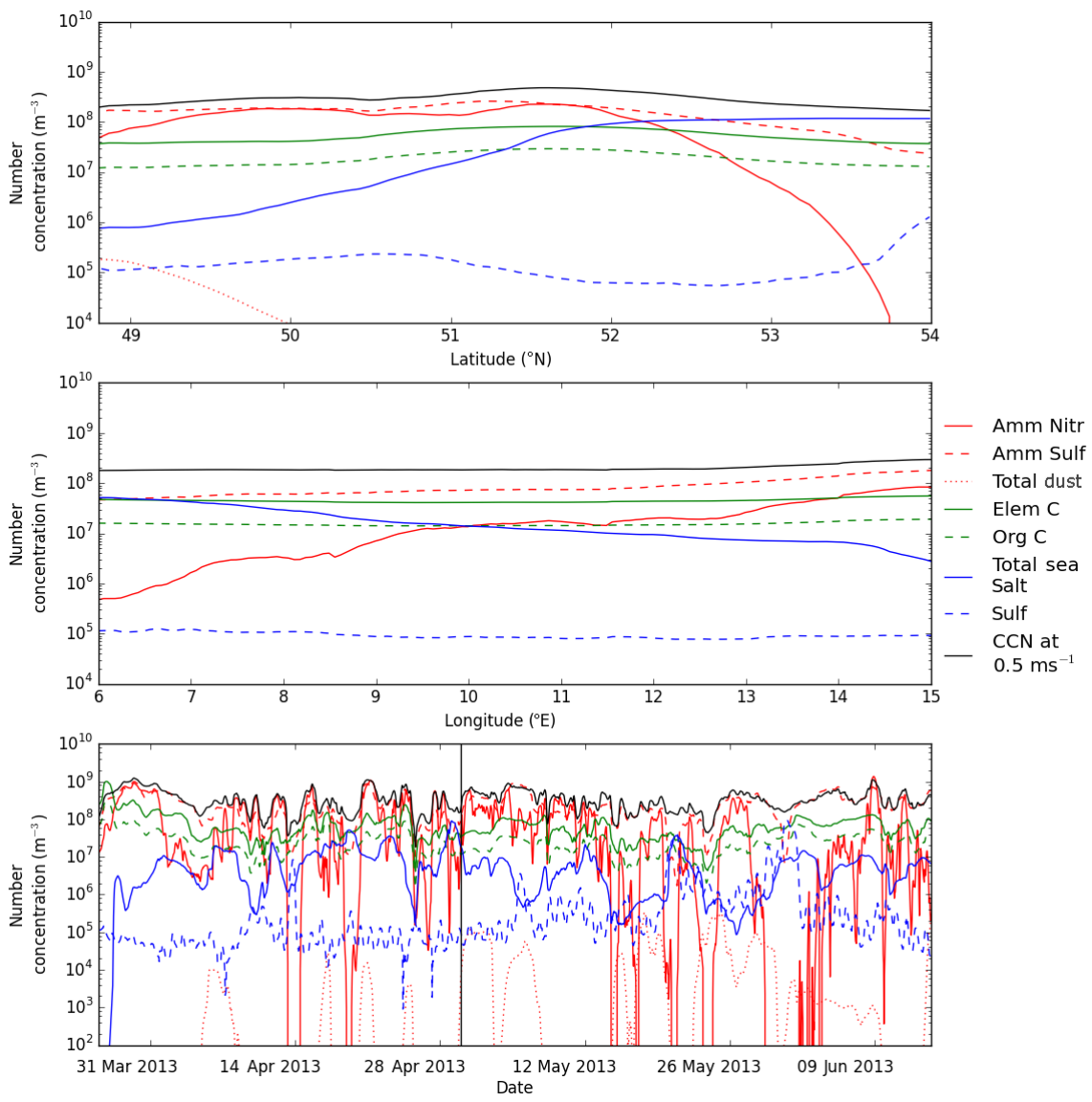

Figure 5. Latitudinal (top) and longitudinal (middle) median number concentration for aerosols and CCN at $0.5 \mathrm{~m} \mathrm{~s}^{-1}$ for 30 April 2013 . Domain-wide median number concentration (bottom) for aerosols and CCN at $0.5 \mathrm{~m} \mathrm{~s}^{-1}$ for the HOPE campaign time period. The solid vertical line indicates the time period of the two upper panels.

of about 1 day are taken, this can be considered to be more constant.

Boucher et al. (2013) also notes that there is low confidence in estimates of the anthropogenic fraction of $\mathrm{CCN}$. In an effort to address this, the fraction that each individual aerosol species contributes to the calculated CCN concentrations is shown in Table 2. Here, CCN concentrations are calculated at a vertical velocity of $0.5 \mathrm{~m} \mathrm{~s}^{-1}$ and, according to Abdul-Razzak et al. (1998), this gives an activated fraction of approximately 0.1 for ammonium sulfate aerosols at $10^{\circ} \mathrm{C}$ and $800 \mathrm{hPa}$. The same activated fraction is found at a supersaturation of approximately $0.2 \%$, which is commonly used by other authors to calculate $\mathrm{CCN}$ concentrations (Pierce and Adams, 2009; Wang and Penner, 2009). Of course this depends on the particular aerosol species, aerosol size, and thermodynamic conditions; however it indicates that the results in Table 2 are roughly comparable to those of other studies.

Table 2 indicates that the $\mathrm{CCN}$ number concentrations over Germany are dominated by $\mathrm{CCN}$ formed on anthropogenic aerosols. Specifically, ammonium sulfate and sulfate dominate $\mathrm{CCN}$ production in the upper levels, and ammonium ni- trate and ammonium sulfate are the dominant aerosols in the lower levels. Although elemental carbon aerosols have a high concentration throughout the atmosphere, their contribution to $\mathrm{CCN}$ is negligible due to the very low hygroscopicity. The sea salt aerosols, which are the most hygroscopic, only play a minor role in $\mathrm{CCN}$ production over the continent. Organic carbon and desert dust aerosols have the same hygroscopicity; therefore the differences in $\mathrm{CCN}$ production are due to differences in the number concentrations of aerosols.

These results are outside the upper bound of estimates of the global mean anthropogenic fraction of CCN. Boucher et al. (2013) combine numerous studies to suggest the anthropogenic fraction of $\mathrm{CCN}$ is between 0.25 and 0.66 ; however the authors did note the large uncertainties and large regional differences in these estimates. Furthermore, sea salt aerosols would be a larger contributor to the global mean, and this would act to reduce the anthropogenic fraction of $\mathrm{CCN}$ compared to the largely continental conditions over Germany. Given that when there are errors in modelled aerosol mass concentrations, the model is biased to lower values compared to the observations, and Table 2 shows the relative contribu- 
Table 2. Percentage contribution of each aerosol species to total CCN number concentrations at $0.5 \mathrm{~m} \mathrm{~s}^{-1}$ for 507 and $906 \mathrm{hPa}$. Each aerosol species is indicated as either anthropogenic $(A)$ or natural $(\mathrm{N})$.

\begin{tabular}{rrrrrr}
\hline \multirow{2}{*}{$507 \mathrm{hPa}$} & Amm nitr (A) & Amm sulf (A) & Elem C (A) & Sulf (A) & Total A \\
\cline { 2 - 6 } & 3.55 & 42.96 & $1.57 \times 10^{-5}$ & 32.58 & 79.09 \\
\hline \multirow{2}{*}{$507 \mathrm{hPa}$} & $2.23 \times 10^{-2}$ & 16.89 & 3.99 & & Total N \\
\hline & Dust (N) & Org C (N) & SS (N) & 20.91 \\
\cline { 2 - 6 } $906 \mathrm{hPa}$ & 46.18 & 46.53 & $1.26 \times 10^{-7}$ & $2.66 \times 10^{-2}$ & 92.74 \\
\hline & Dust $(\mathrm{N})$ & Org C (N) & SS (N) & & Total N \\
\cline { 2 - 6 } $906 \mathrm{hPa}$ & $1.21 \times 10^{-3}$ & 5.24 & 2.02 & & 7.26 \\
\hline
\end{tabular}

tion of modelled aerosols to total CCN. The errors should not affect these results strongly.

\section{Parameterization development}

The previous section demonstrated that the median vertical profile of $\mathrm{CCN}$ number concentrations can be considered representative of the conditions over Germany during the HOPE campaign if short time periods of 1 day are considered. Here, a parameterization of $\mathrm{CCN}$ concentrations is constructed, which is a function of the atmospheric pressure and the vertical velocity. Using the parameterization provided by Abdul-Razzak and Ghan (2000), median CCN number concentrations were calculated at 40 different vertical velocities for each time step of modelled aerosol data. The average over all time steps in 1 day was computed, and this was used to define a series of best fit functions. In this way, aerosol physical and chemical properties are included through the use of Abdul-Razzak and Ghan (2000), as well as the important dependence on the vertical velocity at various pressure levels.

Figure 6 shows the $\mathrm{CCN}$ activation spectrum at each of the 32 pressure levels, for 1 day during HOPE, as well as the average of all data used in this study. Pressure levels closer to the ground have larger CCN number concentrations. The characteristic shape of this activation spectrum can be described at each pressure level by the following relation:

$\mathrm{CCN}(w)=A \times \arctan (B \times \log (w)+C)+D$,

where $\log (w)$ is the natural logarithm of vertical velocity in $\mathrm{m} \mathrm{s}^{-1}$. This best fit function for each pressure level is shown as the red lines in Fig. 6. The fitting was performed by means of a non-linear least squares method, where the data are first approximated by a model, and the model parameters are refined through successive iterations which minimize the errors between the data and model. In Fig. 6, low vertical velocities correspond to low supersaturations, and as a result very
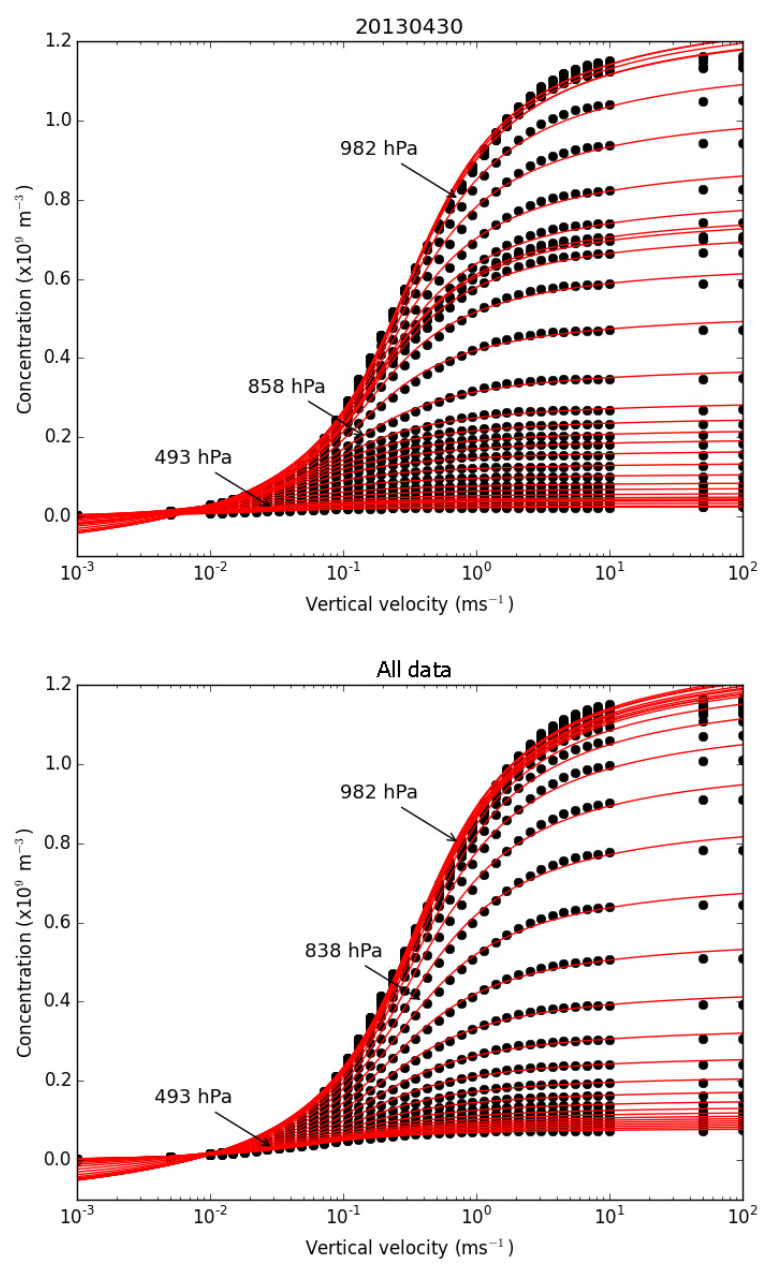

Figure 6. CCN activation spectrum for 30 April 2013 (top) and all data (bottom). Black circles represent the model data, red lines are the best fit functions. 

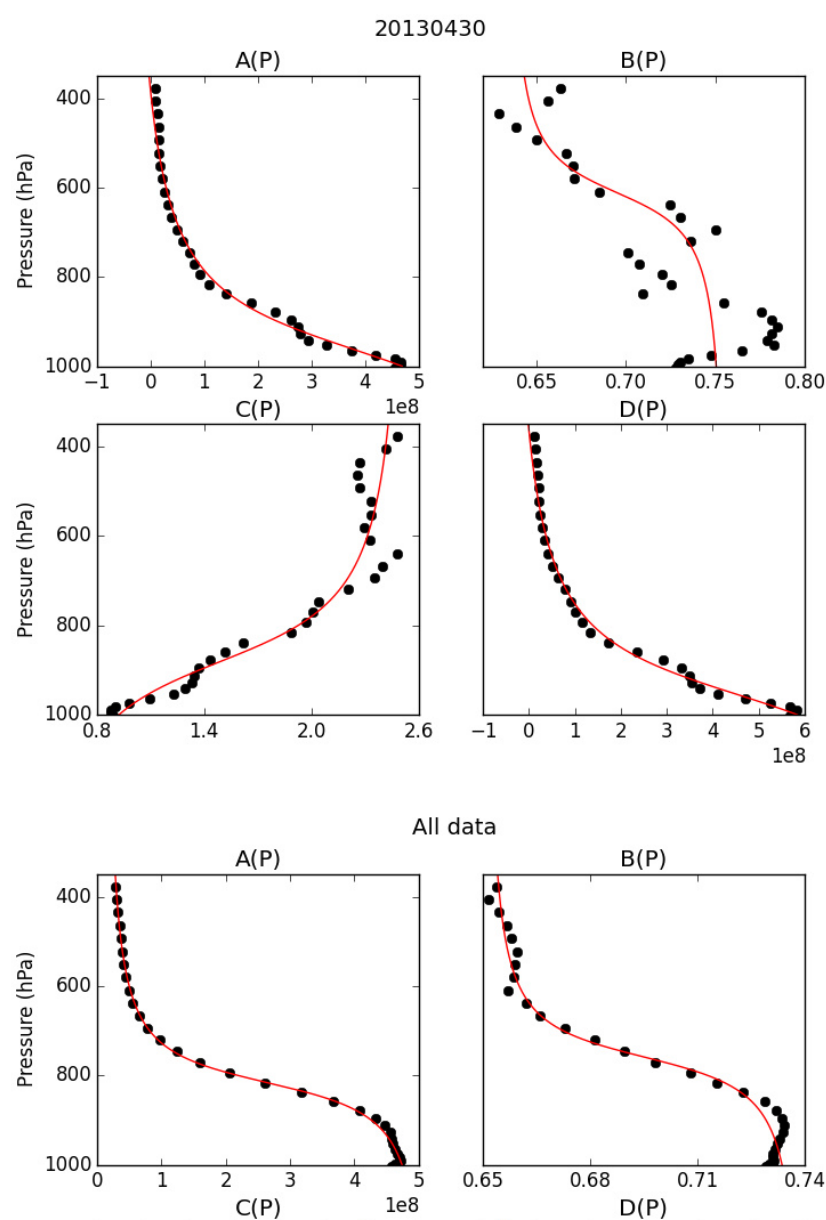

All data
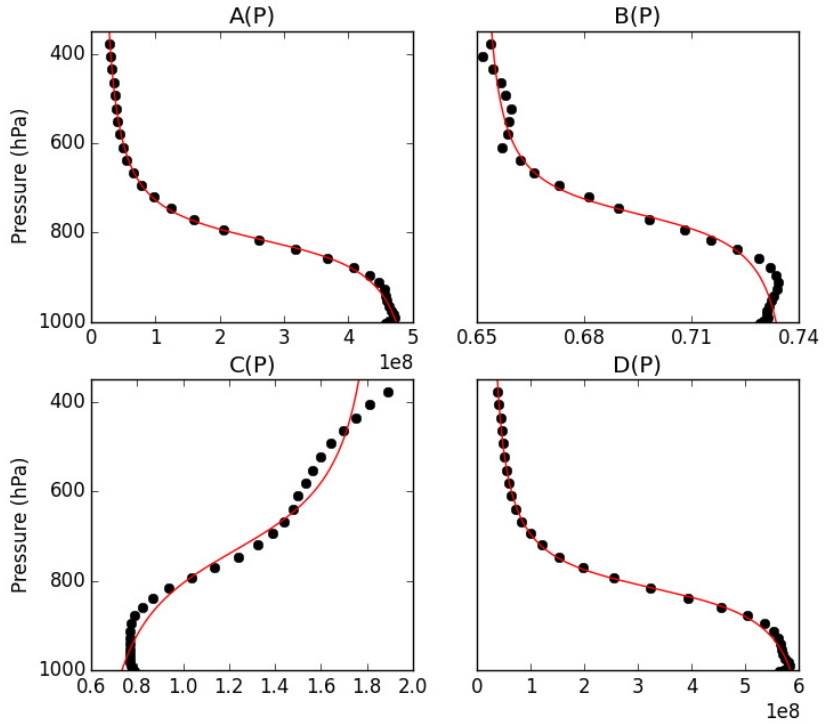

Figure 7. Parameters $A, B, C$, and $D$ as a function of pressure for 30 April 2013 (top) and all data (bottom). Black circles represent the model data, red lines are the best fit functions.

few particles are activated. As the vertical velocity increases, an increasing number of particles are activated, until the activated fraction approaches 1 at high vertical velocities. This relationship is an inherent attribute of the Abdul-Razzak et al. (1998) parameterization and is best described by the arctan function.

This function provides a very good fit to the modelled activation spectrum, particularly in the range of vertical velocities between 0.01 and $50 \mathrm{~m} \mathrm{~s}^{-1}$. At very small vertical velocities, the function can produce negative $\mathrm{CCN}$ number concentrations, particularly for pressure levels closer to the ground.
This is the largest source of discrepancies between the parameterization and the modelled $\mathrm{CCN}$ data. The parameters $A, B, C$, and $D$ act to control the scale, shape, and position of the curve at each pressure level and have a characteristic variation with pressure themselves, as shown in Fig. 7.

Curves of the following form can be fit to each of these parameters:

$A(P)=a_{1} \times \arctan \left(b_{1} \times P+c_{1}\right)+d_{1}$
$B(P)=a_{2} \times \arctan \left(b_{2} \times P+c_{2}\right)+d_{2}$
$C(P)=a_{3} \times \arctan \left(b_{3} \times P+c_{3}\right)+d_{3}$
$D(P)=a_{4} \times \arctan \left(b_{4} \times P+c_{4}\right)+d_{4}$,

where $P$ is pressure in Pascals. In this series of equations, pressure is used as the vertical coordinate. The shape of these curves is influenced by the structure of the atmosphere, and in some cases a different functional form may be more appropriate than Eqs. (2) to (5). The key to developing a parameterization using this technique is that a function of any type can be fit to these parameters. In some examples examined during HOPE, the fit for the $B$ parameter can be poor. This often occurs when there is a second increase in this parameter above about $700 \mathrm{hPa}$. However, the influence this parameter has on the final parameterized $\mathrm{CCN}$ concentrations is small, and it can be seen from the bottom panels of Fig. 7, that on average the fit provided by Eqs. (2) to (5) is very good. Combining Eqs. (1) to (5), the $\mathrm{CCN}$ number concentrations $\left(\mathrm{m}^{-3}\right)$ are defined as follows:

$$
\begin{aligned}
\operatorname{CCN}(w, P) & =A(P) \times \arctan (B(P) \\
& \times \log (w)+C(P))+D(P),
\end{aligned}
$$

where the 16 parameters $a_{1}$ to $d_{4}$ must be defined for each time period. These parameters are provided in Table A1 of Appendix A for each day of HOPE, as well as the mean over the whole time period. Users must first decide which CCN profile suits the needs of their simulation and select the appropriate fit parameters. The domain mean surface pressure, temperature, and vertically integrated specific humidity given in Table A2 may assist in this regard, if users wish to apply them to days not parameterized. The mean CCN profile can be employed for longer simulations not wishing to include daily variability.

Figure 8 shows the parameterization compared to $\mathrm{CCN}$ number concentrations calculated directly from the modelled aerosol data, at multiple vertical velocities. As can be seen, discrepancies between the parameterized CCN concentrations and those calculated directly from the model data are most significant at vertical velocities less than about $0.02 \mathrm{~m} \mathrm{~s}^{-1}$, and pressure levels lower than $800 \mathrm{hPa}$. However, at vertical velocities greater than about $0.1 \mathrm{~m} \mathrm{~s}^{-1}$, the parameterization derived above provides an excellent fit for the modelled CCN concentrations. These larger vertical velocities are most relevant for conditions within clouds. In order 

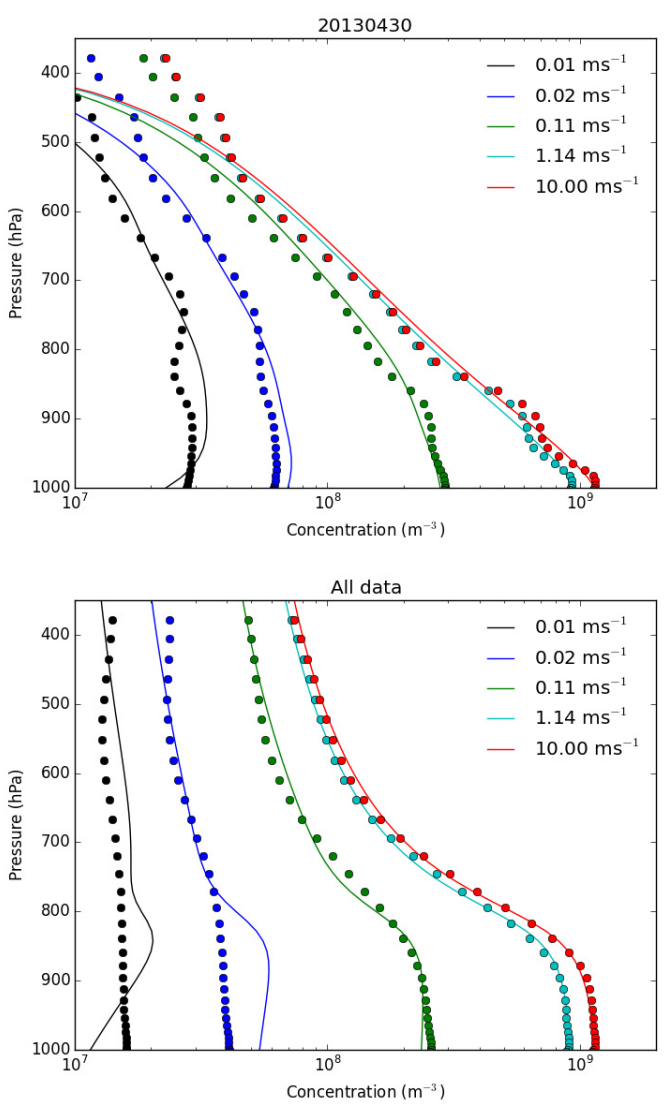

Figure 8. Modelled (circles) and parameterized (lines) CCN concentrations at multiple vertical velocities for 30 April 2013 (top) and all data (bottom).

to prevent unrealistically low $\mathrm{CCN}$ number concentrations, it is recommended to implement a minimum $\mathrm{CCN}$ concentration of $10^{7} \mathrm{~m}^{-3}$.

This approach to parameterizing $\mathrm{CCN}$ concentrations has an advantage over other traditional methods. The CCN parameterization developed by Segal and Khain (2006) assumes a constant $\mathrm{CCN}$ concentration up to a specified height, above which the concentration decreases exponentially. This would only be a suitable representation in the case of a wellmixed boundary layer, with no aerosol and, therefore, no $\mathrm{CCN}$ production in the upper levels. The parameterization developed above is flexible enough to account for an atypical vertical distribution of CCN. For example, the top panel of Fig. 8 shows no well-mixed region, instead an almost linear decrease in $\mathrm{CCN}$ concentrations from the surface through to the mid-troposphere. Furthermore, Fig. 4 implies that sulfate aerosols can be produced in the upper levels; therefore the rate of decrease in $\mathrm{CCN}$ number concentrations above the boundary layer may not be exponential. It is suggested that the vertical profile of $\mathrm{CCN}$ number concentration obtained through this new parameterization provides a more accurate representation.
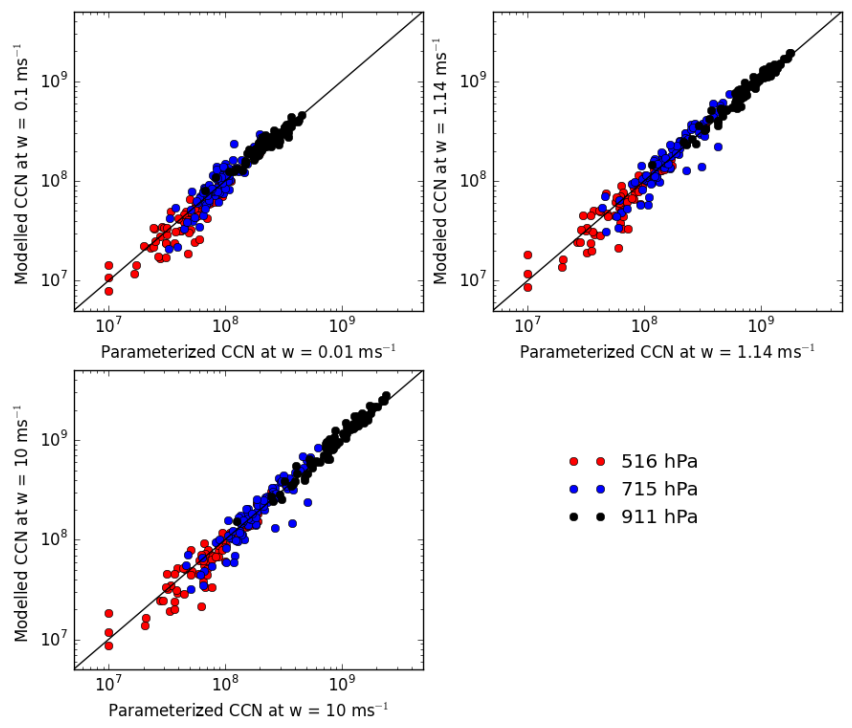

- $516 \mathrm{hPa}$

- $715 \mathrm{hPa}$

- $911 \mathrm{hPa}$

Figure 9. Scatter diagrams of modelled $\mathrm{CCN}$ number concentrations against parameterized $\mathrm{CCN}$ number concentrations, for $w=$ 0.01 (upper left), 1.14 (upper right), and $10 \mathrm{~m} \mathrm{~s}^{-1}$ (lower left), and for 516 (red), 715 (blue), and $911 \mathrm{hPa}$ (black).

Figure 9 shows scatter diagrams of the modelled CCN number concentrations against the parameterized $\mathrm{CCN}$ number concentrations for 3 pressure levels and 3 vertical velocities. Overall, there is no significant bias in the parameterized $\mathrm{CCN}$ number concentrations. At high pressures, the agreement between the parameterized and modelled number concentrations is excellent, but the differences between the two increase with decreasing pressure. At $1.14 \mathrm{~m} \mathrm{~s}^{-1}$, the average absolute magnitudes of the difference between the parameterized and modelled number concentrations are 8,22 , and $22 \%$ of the modelled concentrations at 911,715 , and $516 \mathrm{hPa}$ respectively. The three points at $516 \mathrm{hPa}$ and a parameterized number concentrations of $1 \times 10^{7} \mathrm{~m}^{-3}$ would have very low number concentrations according to Eq. (6), hence the values must be adjusted to a minimum of $1 \times 10^{7} \mathrm{~m}^{-3}$. These profiles are from 9 to 11 April 2013.

To further quantify the quality of the fit, the normalized root mean squared error (nRMSE) for each profile was computed, as shown in Table A2. The maximum nRMSE is 0.1930 for 3 June 2013, the minimum is 0.0127 for 1 April 2013, and the mean nRMSE over all days is 0.0555 , which implies mean errors of $5.55 \%$. A qualitative inspection of the residuals, defined as Abdul-Razzak and Ghan (2000) - Eq. (6), was also made (not shown). The residuals were largest in the lower troposphere, but are still small relative to the maximum concentrations. This indicates that there is a small amount of variability in $\mathrm{CCN}$ concentrations that Eq. (6) does not capture. In the upper levels, the residuals are much closer to zero, which indicates that the form of the parameterization is appropriate for capturing the main features in the vertical distribution of $\mathrm{CCN}$. 


\section{Conclusions}

The COSMO-MUSCAT model was used to simulate the generation and transport of aerosols to Europe during the HOPE campaign. An evaluation of the modelled aerosol concentrations with available observations shows good agreement. The mass concentrations and temporal variability of ammonium sulfate, ammonium nitrate, and sea salt concentrations are in very good agreement with observations from Melpitz. Total $\mathrm{PM}_{2.5}$ concentration is underestimated by the model by a factor of about 2 . The size distribution from the model also agrees well with observations; however there is a slight underestimate at smaller and larger particle sizes.

From these aerosol concentrations, CCN number concentrations were calculated. The analysis demonstrated that while there may be large variability in aerosol concentrations throughout the domain considered here, the spatial variability of the resulting CCN concentrations is significantly lower, typically only varying by a factor of 2 . There is, on the other hand, a larger amount of temporal variability over the time period. This implies that the median vertical profile of $\mathrm{CCN}$ number concentrations is most representative of the conditions over Germany if short time periods are considered.

The anthropogenic fraction of $\mathrm{CCN}$ was found to be large over continental Germany, at over $90 \%$ near the surface, decreasing to about $80 \%$ in the mid-troposphere. This is larger than estimates of the global mean and demonstrates the significant impact that anthropogenic aerosols have on cloud properties.
A parameterization of $\mathrm{CCN}$ number concentrations was developed, using a series of best fit functions to capture the dependency of $\mathrm{CCN}$ activation on vertical velocity at different pressure levels. In this parameterization, the influence of aerosol physical and chemical properties on $\mathrm{CCN}$ are included through the prior use of a detailed aerosol activation scheme. The parameterized CCN number concentrations compare well to the number concentrations calculated directly from the modelled aerosol data, except at very low vertical velocities and pressure levels close to the ground. This represents a new approach for parameterizing CCN for use in models, which to the authors knowledge has not been demonstrated before. As long as the technique provides adequate fits of all the free parameters in Eq. (6), this technique can be employed to parameterize $\mathrm{CCN}$ in other regions and over other time periods.

\section{Data availability}

Data used in this manuscript can be provided upon request by email to the corresponding author, Luke Hande (luke.hande@kit.edu). 


\section{Appendix A}

Table A1. Parameters defining the CCN parameterization.

\begin{tabular}{|c|c|c|c|c|}
\hline $\begin{array}{l}\text { Date } \\
\text { (yyyy-mm-dd) }\end{array}$ & $a_{1}$ & $b_{1}$ & $c_{1}$ & $d_{1}$ \\
\hline 2013-03-26 & 257027511.629 & 0.000199979502434 & -17.6117849009 & 422546964.512 \\
\hline 2013-03-27 & 257259587.478 & 0.000201760653742 & -17.0754515981 & 458225862.794 \\
\hline 2013-03-28 & 248134036.277 & 0.000248771867112 & -19.8502078315 & 486429124.702 \\
\hline 2013-03-29 & 293002066.039 & 0.000225778435403 & -17.3399883006 & 557584166.907 \\
\hline 2013-03-30 & 252381141.108 & 0.000128527088931 & -10.0148105244 & 425988267.377 \\
\hline 2013-03-31 & 315995778.379 & 0.000105411525029 & -8.52132974576 & 476826117.331 \\
\hline 2013-04-01 & 383647486.647 & $9.53987511704 \times 10^{-5}$ & -8.32043216657 & 570523268.512 \\
\hline 2013-04-02 & 324811271.228 & 0.000138642834665 & -12.2490672445 & 530652188.373 \\
\hline 2013-04-03 & 223154550.008 & 0.000210211401757 & -18.2301131592 & 389572102.855 \\
\hline 2013-04-04 & 185174471.514 & 0.00027916990502 & -24.9758011901 & 312654653.088 \\
\hline 2013-04-05 & 123965671.328 & 0.000220481723183 & -20.2930529312 & 214063096.868 \\
\hline 2013-04-06 & 186141937.179 & 0.000119207983665 & -10.6880203951 & 289075639.249 \\
\hline 2013-04-07 & 197619469.896 & 0.000195683880524 & -16.6673454676 & 306111694.706 \\
\hline 2013-04-08 & 228555620.453 & 0.000209968372046 & -18.0177227325 & 353752154.783 \\
\hline 2013-04-09 & 165782282.315 & 0.000158862778002 & -13.3344716637 & 230965254.836 \\
\hline 2013-04-10 & 149088253.239 & 0.000197799417401 & -16.8329323519 & 210898751.656 \\
\hline 2013-04-11 & 188933606.377 & 0.000205926861534 & -18.7422637505 & 277465364.811 \\
\hline 2013-04-12 & 151501378.329 & 0.000154496611164 & -13.3548084787 & 222893897.281 \\
\hline 2013-04-13 & 182711318.548 & 0.000186202391181 & -15.4762408599 & 266493038.479 \\
\hline 2013-04-14 & 165170320.037 & 0.000278508634965 & -26.9803029196 & 260454659.599 \\
\hline & & 0.000105519547855 & -9.51386317268 & 287279759.576 \\
\hline 2013-04-16 & 224420005.659 & 0.000293961293006 & -23.3619212815 & 350287206.787 \\
\hline & & & -22.2848137664 & \\
\hline 2013-04-18 & 66896808.8009 & 0.000622874606996 & -47.5770620781 & 149054005.269 \\
\hline 2013-04-19 & 70902191.9176 & 0.000268682081376 & -22.3654923985 & 113755021.935 \\
\hline 2013-04-20 & 54046034.4806 & 0.000463840088873 & -39.6472498837 & 93778930.966 \\
\hline 2013-04-21 & 237046050.889 & 0.000197584785429 & -15.7411031906 & 354983011.683 \\
\hline 2013-04-22 & 350703557.487 & 0.000248652491121 & -19.1756371885 & 535342752.709 \\
\hline 2013-04-23 & 277648946.464 & 0.000220951487302 & -18.756838732 & 417530444.244 \\
\hline 2013-04-24 & 326536851.625 & 0.000476307032206 & -40.0176304001 & 520404849.951 \\
\hline 2013-04-25 & 297051358.433 & 0.000160822913339 & -12.9411417647 & 437962207.588 \\
\hline 2013-04-26 & 123186926.017 & 0.000195179520486 & -13.4949151996 & 183690869.78 \\
\hline 2013-04-27 & 110210087.645 & 0.000239022945279 & -21.8073672723 & 169437053.325 \\
\hline 2013-04-28 & & 0.00015523807202 & -13.5145674577 & \\
\hline 2013-04-29 & 242468712.867 & 0.0001916705582 & -16.2115926716 & 355241545.175 \\
\hline 2013-04-30 & 268062705.206 & $9.00228432568 \times 10^{-5}$ & -8.67002079484 & 369899109.621 \\
\hline 2013-05-01 & 102511887.928 & 0.000421989534664 & -34.118007519 & 167341263.238 \\
\hline 2013-05-02 & 188914931.006 & 0.000531227091679 & -41.6626456765 & 299914013.763 \\
\hline 2013-05-03 & 166534415.574 & 0.000345442088574 & -27.3432677906 & 257750601.317 \\
\hline 2013-05-04 & 170209024.489 & 0.000349594756448 & -27.9177073888 & 264146914.747 \\
\hline 2013-05-05 & 169785924.886 & 0.000831242458893 & -66.8062397787 & 285125428.499 \\
\hline 2013-05-06 & 278790529.473 & 0.000451534894898 & -34.9583814579 & 443180679.414 \\
\hline 2013-05-07 & 242323023.311 & 0.000233685933182 & -17.7939128097 & 367463885.465 \\
\hline 2013-05-08 & 274335739.495 & 0.000213306540004 & -17.0245331362 & 412727950.786 \\
\hline 2013-05-09 & 113333109.973 & 0.000509886806569 & -38.659883261 & 195376416.716 \\
\hline 2013-05-10 & 105744547.317 & 0.000538143118997 & -42.6695357287 & 172643018.723 \\
\hline 2013-05-11 & 162385382.85 & 0.000332727679016 & -26.8845754909 & 251110679.598 \\
\hline 2013-05-12 & 102248916.147 & 0.000541014965278 & -43.8361853001 & 175912999.174 \\
\hline $2013-05-13$ & 143779878.725 & 0.000155656177112 & -13.6193322737 & 227494184.849 \\
\hline
\end{tabular}


Table A1. Continued.

\begin{tabular}{|c|c|c|c|c|}
\hline $\begin{array}{l}\text { Date } \\
\text { (yyyy-mm-dd) }\end{array}$ & $a_{1}$ & $b_{1}$ & $c_{1}$ & $d_{1}$ \\
\hline 2013-05-14 & 118394120.321 & 0.000336419574937 & -28.0940496016 & 211132273.023 \\
\hline 2013-05-15 & 137515734.708 & 0.000205753839294 & -16.8745414588 & 227625697.257 \\
\hline 2013-05-16 & 161976926.272 & 0.000200490706083 & -16.4967738319 & 240382761.941 \\
\hline $2013-05-17$ & 177831147.397 & 0.000101960076261 & -9.76398595204 & 260133006.929 \\
\hline 2013-05-18 & 104881119.861 & 0.000246405889005 & -21.9696591509 & 182569272.058 \\
\hline 2013-05-19 & 179777743.64 & 0.0002080697608 & -18.6108519411 & 285371721.017 \\
\hline 2013-05-20 & 118821569.691 & 0.000222886738303 & -18.7921495959 & 204363017.191 \\
\hline 2013-05-21 & 165508396.77 & 0.000114815803897 & -9.84950957879 & 250730495.161 \\
\hline 2013-05-22 & 70615209.8813 & $3.32596702867 \times 10^{-5}$ & -2.98203668112 & 102740204.691 \\
\hline $2013-05-23$ & 33784879.7638 & 0.000246796867986 & -20.6103783055 & 95065841.3682 \\
\hline $2013-05-24$ & 69249667.1912 & 0.000191067256933 & -16.0354837343 & 133852326.6 \\
\hline $2013-05-25$ & 115027389.491 & $7.61382715981 \times 10^{-5}$ & -7.37537621712 & 172994343.375 \\
\hline $2013-05-26$ & 37450539.3977 & 0.000368115275095 & -33.830244913 & 72896973.5148 \\
\hline 2013-05-27 & 101409398.615 & 0.000128765200546 & -10.8783417297 & 159533090.217 \\
\hline $2013-05-28$ & 238929584.969 & $8.95306448836 \times 10^{-5}$ & -7.49168205554 & 314416272.56 \\
\hline 2013-05-29 & 238883906.14 & 0.000151184644169 & -12.2144440358 & 342930672.175 \\
\hline 2013-05-30 & 174563406.955 & 0.000213620483956 & -17.1817084836 & 289090000.942 \\
\hline 2013-05-31 & 112478707.879 & 0.000142127082463 & -11.0733353463 & 194024530.85 \\
\hline 2013-06-01 & 338306772.546 & $3.61392403177 \times 10^{-5}$ & -4.09357557336 & 439858074.785 \\
\hline 2013-06-02 & 13434965.7592 & 0.000925991878154 & -83.7326610938 & 112739974.004 \\
\hline 2013-06-03 & 30168723.3708 & 0.000495944658031 & -44.0243294791 & 126010850.256 \\
\hline 2013-06-04 & 97237112.3611 & $7.26358090841 \times 10^{-5}$ & -6.24517522307 & 190489849.419 \\
\hline 2013-06-05 & 82203983.0014 & 0.000116274085792 & -9.47442018757 & 176075128.011 \\
\hline 2013-06-06 & 86173034.7384 & 0.000383182474213 & -29.5769436462 & 191563430.341 \\
\hline 2013-06-07 & 135064790.26 & 0.000388462942097 & -29.6327517089 & 263840022.66 \\
\hline 2013-06-08 & 165886739.585 & 0.000416275919247 & -31.8020906757 & 315914626.231 \\
\hline 2013-06-09 & 132133978.232 & 0.000232190223914 & -17.8646334752 & 248371577.344 \\
\hline 2013-06-10 & 118866967.784 & 0.000150818334962 & -12.5455428262 & 212616425.951 \\
\hline 2013-06-11 & 192876867.075 & 0.000221833101314 & -17.4557128001 & 329976771.525 \\
\hline 2013-06-12 & 331533472.985 & 0.000304652092061 & -24.1376489102 & 538001096.899 \\
\hline 2013-06-13 & 121083645.226 & 0.000303472188084 & -25.3943799881 & 232222942.427 \\
\hline 2013-06-14 & 101662155.522 & 0.00128461981711 & -104.950293772 & 217280192.35 \\
\hline 2013-06-15 & 125114045.253 & 0.00164830616793 & -127.12314395 & 257013581.432 \\
\hline 2013-06-16 & 85205897.7055 & 0.00079239927885 & -65.1012178105 & 179403546.146 \\
\hline All Data & 163284250.556 & 0.000180120078194 & -14.7056272648 & 265362821.369 \\
\hline $\begin{array}{l}\text { Date } \\
\text { (yyyy-mm-dd) }\end{array}$ & $a_{2}$ & $b_{2}$ & $c_{2}$ & $d_{2}$ \\
\hline 2013-03-26 & -0.029814839848 & 0.000163327802941 & -10.4068100415 & 0.6769189828 \\
\hline 2013-03-27 & -0.0325852534009 & 0.000276069056108 & -12.8380343988 & 0.757535237671 \\
\hline 2013-03-28 & -0.0119185706848 & -0.00292288814881 & 232.270889355 & 0.757360519289 \\
\hline 2013-03-29 & -0.0188580074505 & -0.00373049506288 & 286.859628744 & 0.781750394241 \\
\hline 2013-03-30 & -0.0229861235094 & -0.00337830269291 & 251.75895753 & 0.775685065229 \\
\hline 2013-03-31 & 0.0151256499305 & 0.0011388666053 & -89.3979117485 & 0.770358316613 \\
\hline 2013-04-01 & 0.0189951868813 & 0.000514633362646 & -44.3398908414 & 0.756453767604 \\
\hline 2013-04-02 & 0.0155879769898 & 0.000531979507126 & -46.1373434796 & 0.764685259415 \\
\hline 2013-04-03 & 0.0160831365488 & 0.0103282444131 & -866.529699837 & 0.7433128158 \\
\hline 2013-04-04 & 0.0143849209764 & 0.0498638233939 & -4377.47891107 & 0.739026494198 \\
\hline 2013-04-05 & 0.00760368959733 & 0.0251201147357 & -2329.11898411 & 0.720049432984 \\
\hline 2013-04-06 & 0.0111568649285 & 0.00411606061595 & -387.334321658 & 0.72518267401 \\
\hline 2013-04-07 & 0.0113855040451 & 0.00828281993024 & -710.993665143 & 0.719959884286 \\
\hline 2013-04-08 & 0.0130949075301 & 0.0013770247057 & -118.658153493 & 0.731955333102 \\
\hline 2013-04-09 & -0.0501207426563 & 0.000111624214554 & -5.90812593792 & 0.796894769498 \\
\hline 2013-04-10 & -0.044333962825 & 0.00022764067347 & -15.8680346727 & 0.776901997407 \\
\hline 2013-04-11 & -0.0180182385636 & 0.00851026594054 & -634.547291807 & 0.743204805806 \\
\hline
\end{tabular}


Table A1. Continued.

\begin{tabular}{|c|c|c|c|c|}
\hline $\begin{array}{l}\text { Date } \\
\text { (yyyy-mm-dd) }\end{array}$ & $a_{2}$ & $b_{2}$ & $c_{2}$ & $d_{2}$ \\
\hline 2013-04-12 & -0.0348227896411 & 0.000147753516038 & -6.48537246095 & 0.745624009049 \\
\hline 2013-04-13 & 0.00794151096456 & 0.00107642641128 & -85.8373757326 & 0.715935780732 \\
\hline 2013-04-14 & 0.038693640436 & 0.000410451577778 & -20.1021023967 & 0.668367404449 \\
\hline 2013-04-15 & 0.126571719449 & $3.80199857817 \times 10^{-5}$ & -1.26567516392 & 0.571940577379 \\
\hline 2013-04-16 & 0.0442953079199 & 0.000245814787742 & -17.7011580749 & 0.703578821734 \\
\hline 2013-04-17 & 0.0614177873846 & $7.5554755103 \times 10^{-5}$ & -5.69776314638 & 0.649860475407 \\
\hline 2013-04-18 & 0.0557206584146 & 0.00049403679403 & -34.1444505909 & 0.598701901089 \\
\hline 2013-04-19 & -0.0107608339541 & 0.000510072770769 & -35.8890069504 & 0.702770937226 \\
\hline 2013-04-20 & -0.0340616320637 & 0.00589359697711 & -325.81712188 & 0.731052515565 \\
\hline 2013-04-21 & 0.0196400746521 & 0.000599383945072 & -44.1324325861 & 0.70371451307 \\
\hline 2013-04-22 & 0.0527699977656 & 0.000248259433057 & -17.2667172986 & 0.72497660722 \\
\hline 2013-04-23 & 0.047931663221 & 0.000607996993056 & -47.3945691166 & 0.704347498783 \\
\hline 2013-04-24 & 0.0453353322421 & 0.000623698149368 & -50.6528180808 & 0.709324351895 \\
\hline 2013-04-25 & 65.4475055841 & 0.00580511453284 & -28.9358471088 & -101.913230262 \\
\hline 2013-04-26 & 0.0104486344817 & 0.00122908611961 & -91.5241853954 & 0.720829904429 \\
\hline 2013-04-27 & -0.0286421389331 & 0.00028807078372 & -22.0346749088 & 0.757250590893 \\
\hline 2013-04-28 & -0.0274886165954 & 0.00377253418203 & -230.845564031 & 0.752272034805 \\
\hline 2013-04-29 & 25.5809712348 & 0.000282584826916 & 32.8793907769 & -38.9937575255 \\
\hline 2013-04-30 & -0.0368311926571 & -0.000174258591758 & 10.7064355564 & 0.6952993282 \\
\hline 2013-05-01 & 0.0135912432763 & 0.00116628079855 & -99.2069395798 & 0.702624978333 \\
\hline 2013-05-02 & 0.0248350654338 & 0.00134800400185 & -100.069936639 & 0.721198815048 \\
\hline 2013-05-03 & -0.0153572204661 & -0.00257925380382 & 204.769223034 & 0.724407784298 \\
\hline 2013-05-04 & -0.0155709142123 & -0.00268073465594 & 212.924912417 & 0.724410206287 \\
\hline 2013-05-05 & 0.0493431363349 & 0.00255746079276 & -197.216212945 & 0.681033689362 \\
\hline 2013-05-06 & 0.0304348752283 & 0.00138822910198 & -107.67165669 & 0.739122705985 \\
\hline 2013-05-07 & -0.0189563211661 & -0.00193158996003 & 142.888007811 & 0.743541868199 \\
\hline 2013-05-08 & -0.0204945766538 & -0.000732603490207 & 55.5005987103 & 0.747655947116 \\
\hline 2013-05-09 & 0.0300211673167 & $7.7947799912 \times 10^{-5}$ & -5.68853442875 & 0.722837967764 \\
\hline 2013-05-10 & -0.0213618854837 & 0.000274733904033 & -17.028199312 & 0.743374798773 \\
\hline 2013-05-11 & -2.46552737502 & 0.0151246299239 & -1582.41924306 & -3.12072758678 \\
\hline 2013-05-12 & -0.0139017663139 & 0.00027851620683 & -26.8682695389 & 0.714771501715 \\
\hline $2013-05-13$ & 0.0124283474368 & 0.000545650574569 & -42.0000886773 & 0.697747611773 \\
\hline 2013-05-14 & 0.0034283474368 & 0.000545650574569 & -42.0000886773 & 0.697747611773 \\
\hline 2013-05-15 & -0.0367444689868 & -0.000122747784463 & 10.5573007709 & 0.725675639967 \\
\hline 2013-05-16 & -0.810832542971 & 0.00576822448077 & -640.398614387 & -0.506710196986 \\
\hline 2013-05-17 & 0.0234593664171 & 0.00102200286985 & -97.493789532 & 0.76298549245 \\
\hline 2013-05-18 & 0.0374535870591 & $4.46584613895 \times 10^{-5}$ & -2.64686634671 & 0.722042807921 \\
\hline 2013-05-19 & 0.0129138591047 & 0.000520191639983 & -47.1399467981 & 0.726974314612 \\
\hline 2013-05-20 & 0.0399072344891 & $5.36824439419 \times 10^{-5}$ & -5.15883256757 & 0.746774023727 \\
\hline 2013-05-21 & 0.00916153210837 & 0.0227872535083 & -2000.5631296 & 0.730351283666 \\
\hline $2013-05-22$ & -0.00867734260577 & 0.000878994804728 & -54.5253166078 & 0.688136048799 \\
\hline $2013-05-23$ & -0.084237316917 & $-3.51587495995 \times 10^{-7}$ & -1.46957040783 & 0.594308505026 \\
\hline 2013-05-24 & -0.00979403232467 & 0.001467664618 & -72.2430777115 & 0.708502064111 \\
\hline 2013-05-25 & -0.1 & $5 \times 10^{-5}$ & -0.5 & 0.83 \\
\hline $2013-05-26$ & 0.0226974956012 & -0.000287634445498 & 25.1370934599 & 0.7246471921 \\
\hline $2013-05-27$ & -0.00900416329567 & 0.0049821811569 & -371.553867706 & 0.723009419426 \\
\hline $2013-05-28$ & 0.00452308088149 & 0.00886821690033 & -834.202826692 & 0.747028286906 \\
\hline 2013-05-29 & -0.00735146323438 & -0.921419025165 & 77260.9872538 & 0.748615624012 \\
\hline 2013-05-30 & -0.0213661981303 & -0.000869381872845 & 65.5156529736 & 0.723557314935 \\
\hline 2013-05-31 & 0.0156975384075 & 0.000927882265059 & -69.8025212366 & 0.714998416504 \\
\hline 2013-06-01 & 0.0119317574675 & 0.00266166236376 & -198.324400697 & 0.692168966081 \\
\hline 2013-06-02 & 0.0197813156726 & 0.00148349415601 & -130.052548417 & 0.675923345178 \\
\hline 2013-06-03 & 0.010118651257 & -0.000978730377931 & 39.631928973 & 0.674753205687 \\
\hline 2013-06-04 & 0.0112288905438 & 0.00213132765181 & -174.76139083 & 0.662941933206 \\
\hline
\end{tabular}


Table A1. Continued.

\begin{tabular}{|c|c|c|c|c|}
\hline $\begin{array}{l}\text { Date } \\
\text { (yyyy-mm-dd) }\end{array}$ & $a_{2}$ & $b_{2}$ & $c_{2}$ & $d_{2}$ \\
\hline 2013-06-05 & 0.0121120858222 & 0.00074709092356 & -60.0364656402 & 0.676774244876 \\
\hline 2013-06-06 & 0.0154334027655 & 0.024281754693 & -1871.23983096 & 0.696513907984 \\
\hline 2013-06-07 & 0.0251669347664 & 0.00051606046222 & -38.4607550706 & 0.722091560856 \\
\hline 2013-06-08 & 0.0432657151129 & 0.000406591616308 & -30.4276024142 & 0.75392995781 \\
\hline 2013-06-09 & 0.0381896488685 & 0.000337345832544 & -25.3217372648 & 0.744838180739 \\
\hline 2013-06-10 & 0.0250429932744 & 0.000562960816431 & -47.862698352 & 0.720779691293 \\
\hline 2013-06-11 & 0.0384101319177 & 0.000386555829788 & -27.7369231426 & 0.717952241602 \\
\hline 2013-06-12 & 0.0459899436012 & 0.000844692260638 & -60.9483594953 & 0.73761297588 \\
\hline 2013-06-13 & -0.020158885649 & -0.0276287029505 & 2256.96907061 & 0.713505498794 \\
\hline 2013-06-14 & -0.0113154472794 & -0.002921470433 & 226.028584109 & 0.704349149996 \\
\hline 2013-06-15 & -0.0187435029412 & -0.00111456487272 & 81.7455206955 & 0.708851574533 \\
\hline 2013-06-16 & 0.00408842837182 & -0.00716541146274 & 332.112579081 & 0.70950778351 \\
\hline All Data & -0.0288027446725 & -0.000171569387007 & 13.0270839469 & 0.695246510346 \\
\hline $\begin{array}{l}\text { Date } \\
\text { (yyyy-mm-dd) }\end{array}$ & $a_{3}$ & $b_{3}$ & $c_{3}$ & $d_{3}$ \\
\hline 2013-03-26 & -1.25999010727 & $2.68241230633 \times 10^{-5}$ & -1.72213638658 & 1.65350478005 \\
\hline 2013-03-27 & -1.7839755869 & $1.50929337952 \times 10^{-5}$ & -0.837612435568 & 1.85077964544 \\
\hline 2013-03-28 & -146.099540152 & 0.000225138533191 & 22.1232658493 & 226.964569092 \\
\hline 2013-03-29 & -1.34131727013 & $2.50404007492 \times 10^{-5}$ & -1.09710211005 & 1.97401126273 \\
\hline 2013-03-30 & -373.973073375 & 0.0022301585943 & 42.4980960204 & 586.904883742 \\
\hline 2013-03-31 & -1.32071946789 & $2.10784161196 \times 10^{-5}$ & -1.44735197002 & 1.50783743906 \\
\hline & -595.988540448 & 0.00156838963697 & 76.2162181865 & 934.332741347 \\
\hline 2013-04-02 & -429.287209778 & 0.00195353999206 & 43.2591431888 & 673.300179085 \\
\hline 2013-04-03 & -354.397239742 & 0.00307301913246 & 3.24827794838 & 556.439227008 \\
\hline 2013-04-04 & -722.862758695 & 0.00304393888477 & 82.1984554958 & 1134.66288854 \\
\hline 2013-04-05 & -333.95573167 & 0.000784293626916 & 51.1205832771 & 523.196754074 \\
\hline 2013-04-06 & -408.652449376 & 0.00210744511673 & 33.5160310077 & 641.285679271 \\
\hline 2013-04-07 & -0.931285878466 & $4.62239563217 \times 10^{-5}$ & -3.30289909524 & 1.73383064603 \\
\hline 2013-04-08 & -0.70989332512 & $7.55580178287 \times 10^{-5}$ & -5.81108685449 & 1.5574853692 \\
\hline 2013-04-09 & -1.28261872563 & $6.96289413036 \times 10^{-5}$ & -4.76372043972 & 2.40211987664 \\
\hline 2013-04-10 & -1.08990759738 & 0.000130523268638 & -9.65260135541 & 2.25019366451 \\
\hline 2013-04-11 & -0.695966886536 & 0.000154729891348 & -12.4511039248 & 1.73172754779 \\
\hline 2013-04-12 & -1.24717832619 & $4.82341633583 \times 10^{-5}$ & -3.32321347743 & 2.08047919673 \\
\hline 2013-04-13 & -0.882943394797 & $8.03509209991 \times 10^{-5}$ & -5.77611904313 & 1.81629983255 \\
\hline & -0.287194877967 & 0.000600945728595 & -54.0848223318 & 1.42466992937 \\
\hline 2013-04-15 & -0.418486879565 & 0.000116279302557 & -9.34929026635 & 1.27060902036 \\
\hline 2013-04-16 & -0.463181171817 & 0.000229124424724 & -17.6024080361 & 1.29279832853 \\
\hline 2013-04-17 & 0.222918696941 & -0.000394632485796 & 34.0018788402 & 1.18445134078 \\
\hline 2013-04-18 & 0.147889372175 & -0.00164037984568 & 126.698112989 & 1.25228964998 \\
\hline 2013-04-19 & -0.60286179518 & 0.000183648686699 & -14.6929427448 & 1.96169583431 \\
\hline 2013-04-20 & -239.2009653 & 0.00104803671278 & 16.9061486135 & 375.304688779 \\
\hline 2013-04-21 & -0.849345878016 & $9.20681792757 \times 10^{-5}$ & -5.61903889161 & 1.72632960381 \\
\hline 2013-04-22 & -0.714584192015 & $9.21357895543 \times 10^{-5}$ & -5.97479789522 & 1.37126784234 \\
\hline 2013-04-23 & -0.424938795281 & 0.000192261099352 & -15.8346004825 & 1.20278591386 \\
\hline 2013-04-24 & -0.465259558225 & 0.000237161116198 & -19.1049134773 & 1.08031121538 \\
\hline 2013-04-25 & -0.475503560527 & 0.000192355777417 & -13.230688361 & 1.18762265562 \\
\hline 2013-04-26 & -0.691019498158 & 0.000139959391683 & -7.99850700522 & 1.73153075465 \\
\hline 2013-04-27 & -0.81914143666 & 0.000119282661856 & -10.0243823956 & 1.87746719768 \\
\hline 2013-04-28 & -0.860513412579 & 0.000129941958131 & -8.72046968585 & 2.06156811575 \\
\hline 2013-04-29 & -0.615207577704 & 0.000119808650723 & -9.44135316974 & 1.46338145959 \\
\hline 2013-04-30 & -0.68509594868 & $9.07655415297 \times 10^{-5}$ & -7.99865058891 & 1.49322380511 \\
\hline 2013-05-01 & -0.519654567659 & 0.000317800267516 & -24.2286991499 & 1.7689389708 \\
\hline
\end{tabular}


Table A1. Continued.

\begin{tabular}{|c|c|c|c|c|}
\hline $\begin{array}{l}\text { Date } \\
\text { (yyyy-mm-dd) }\end{array}$ & $a_{3}$ & $b_{3}$ & $c_{3}$ & $d_{3}$ \\
\hline 2013-05-02 & -1.11280140047 & $6.61309288082 \times 10^{-5}$ & -4.27951113912 & 2.00538429673 \\
\hline 2013-05-03 & -0.88579724448 & 0.000110564000686 & -7.32585831853 & 1.98284339015 \\
\hline 2013-05-04 & -1.61464525376 & $3.80749098093 \times 10^{-5}$ & -2.1436750988 & 2.36446975491 \\
\hline $2013-05-05$ & -0.943848160565 & $6.36900365619 \times 10^{-5}$ & -3.90882328996 & 1.8565436722 \\
\hline $2013-05-06$ & -1.07934637213 & $7.62165327465 \times 10^{-5}$ & -4.74010349215 & 1.71873623378 \\
\hline 2013-05-07 & -1.36286264208 & $4.04236815208 \times 10^{-5}$ & -2.20999762053 & 1.8481752194 \\
\hline 2013-05-08 & -0.925933829895 & $6.36315473856 \times 10^{-5}$ & -4.38246112807 & 1.35966523239 \\
\hline 2013-05-09 & -0.378846961048 & 0.000429287390377 & -31.5025875823 & 1.44685075948 \\
\hline 2013-05-10 & -0.501317389762 & 0.000240832427312 & -17.5918818622 & 1.67320066174 \\
\hline 2013-05-11 & -0.53908011762 & 0.00024339432442 & -18.7836022684 & 1.57130610445 \\
\hline $2013-05-12$ & -0.402134260333 & 0.000391241509497 & -31.0299472561 & 1.62070840147 \\
\hline 2013-05-13 & -0.288871536496 & 0.000280973683123 & -23.4245054386 & 1.37866424205 \\
\hline 2013-05-14 & -0.276208791978 & 0.000520773251996 & -43.3298210327 & 1.33971395101 \\
\hline 2013-05-15 & -0.513895360814 & $8.87032633236 \times 10^{-5}$ & -6.7520351196 & 1.27851494147 \\
\hline 2013-05-16 & -0.560269238461 & 0.000170241511331 & -13.1700323447 & 1.32265526036 \\
\hline 2013-05-17 & -0.444450818361 & $9.1000429623 \times 10^{-5}$ & -7.21512256963 & 1.35172979657 \\
\hline 2013-05-18 & -0.431046664338 & 0.000115546206148 & -9.96130554955 & 1.32730747833 \\
\hline 2013-05-19 & -0.393353450063 & 0.000173858132453 & -14.235403816 & 1.24108992813 \\
\hline 2013-05-20 & -0.407133122621 & $9.89756705673 \times 10^{-5}$ & -7.62420964636 & 1.37204332133 \\
\hline $2013-05-21$ & -1.06704378015 & $3.16238550312 \times 10^{-5}$ & -2.10909965547 & 1.70820098197 \\
\hline 2013-05-22 & 0.2510147687 & -0.0001695851547 & 7.56871998468 & 1.86473578811 \\
\hline $2013-05-23$ & -64.5312765505 & 0.00194892982989 & 16.3110676014 & 102.580813222 \\
\hline $2013-05-24$ & -1.32499731808 & $1.36299598588 \times 10^{-5}$ & -1.16960888077 & 1.40358746653 \\
\hline $2013-05-25$ & -0.682952076821 & $5.3403772624 \times 10^{-5}$ & -2.679349403 & 2.08151597839 \\
\hline $2013-05-26$ & -0.32371095904 & 0.000148330227646 & -13.3141113038 & 1.66721014705 \\
\hline 2013-05-27 & -0.427495645381 & 0.00011677249743 & -9.14350543479 & 1.43762910725 \\
\hline $2013-05-28$ & -0.927383001908 & $5.1673406534 \times 10^{-5}$ & -3.34816420136 & 1.69833286141 \\
\hline 2013-05-29 & -0.883501696306 & $6.47564972491 \times 10^{-5}$ & -4.37389872681 & 1.61543660421 \\
\hline $2013-05-30$ & -0.548098680953 & $6.73303475323 \times 10^{-5}$ & -5.12858774595 & 1.15082901139 \\
\hline $2013-05-31$ & -0.333808236562 & $7.62249200252 \times 10^{-5}$ & -5.54005586951 & 1.16717121961 \\
\hline 2013-06-01 & -370.325906495 & 0.00359677728395 & 87.2231226264 & 581.821654579 \\
\hline 2013-06-02 & 0.0823717404931 & 0.00477201837839 & -390.188669834 & 1.3230371111 \\
\hline 2013-06-03 & 0.135609478302 & -0.000729429424034 & 33.9764068217 & 1.35421490863 \\
\hline 2013-06-04 & 96.1299450025 & -0.000738569484517 & -51.4460304317 & 151.183926683 \\
\hline 2013-06-05 & 77.9952592775 & -0.000116237778984 & 43.7683935449 & -119.169528436 \\
\hline 2013-06-06 & -132.792420633 & 0.0011597576875 & 32.1840335634 & 208.466060446 \\
\hline 2013-06-07 & -0.498814169354 & $4.75358934694 \times 10^{-5}$ & -3.05512740933 & 1.13789325174 \\
\hline 2013-06-08 & -0.306538568777 & 0.000251163616886 & -18.0807183492 & 1.03227497804 \\
\hline 2013-06-09 & -0.285724374574 & 0.000218245524802 & -15.0935485458 & 1.22397376321 \\
\hline 2013-06-10 & -0.374092574015 & $7.6645726738 \times 10^{-5}$ & -5.42099078016 & 1.35984067623 \\
\hline 2013-06-11 & -0.32529828655 & 0.000161996594323 & -12.1604750317 & 1.09488722572 \\
\hline 2013-06-12 & -0.331937538165 & 0.000291377512412 & -22.836799656 & 0.82718268609 \\
\hline 2013-06-13 & 0.144601621176 & -0.00045898983022 & 39.7459325336 & 0.961554360906 \\
\hline 2013-06-14 & -0.173194732078 & 0.000971333233174 & -78.8987838138 & 1.10277014402 \\
\hline 2013-06-15 & -0.219682412065 & 0.000723465343821 & -55.7467841028 & 1.07610272578 \\
\hline 2013-06-16 & -0.169997837704 & 0.000748813288464 & -62.7335523194 & 1.13678591019 \\
\hline All Data & -0.436109722435 & $7.71432656612 \times 10^{-5}$ & -5.65244631785 & 1.22261713713 \\
\hline
\end{tabular}


Table A1. Continued.

\begin{tabular}{|c|c|c|c|c|}
\hline $\begin{array}{l}\text { Date } \\
\text { (yyyy-mm-dd) }\end{array}$ & $a_{4}$ & $b_{4}$ & $c_{4}$ & $d_{4}$ \\
\hline 2013-03-26 & 302649571.476 & 0.000202604673235 & -17.8601818352 & 505395811.033 \\
\hline 2013-03-27 & 309844331.918 & 0.000201553447317 & -17.0889369229 & 558425882.48 \\
\hline $2013-03-28$ & 303587929.431 & 0.000251184401777 & -20.0776058128 & 600415097.602 \\
\hline 2013-03-29 & 358319870.576 & 0.000235307642443 & -18.109198242 & 689285340.24 \\
\hline 2013-03-30 & 306411494.19 & 0.000130502738578 & -10.2047241636 & 525245208.824 \\
\hline 2013-03-31 & 388602484.531 & 0.000106640142718 & -8.63617368737 & 591782562.502 \\
\hline 2013-04-01 & 476072376.341 & $9.54062745542 \times 10^{-5}$ & -8.34686788976 & 712002557.477 \\
\hline 2013-04-02 & 400738826.224 & 0.000137261994404 & -12.1441852379 & 657786306.277 \\
\hline 2013-04-03 & 271154223.173 & 0.000211618554738 & -18.375924686 & 477963001.566 \\
\hline 2013-04-04 & 222005914.307 & 0.000288026568537 & -25.7839773553 & 380103114.138 \\
\hline 2013-04-05 & 146113683.536 & 0.000226728363976 & -20.8773726066 & 258303073.087 \\
\hline 2013-04-06 & 227357309.834 & 0.000119261373742 & -10.6947244824 & 356992826.431 \\
\hline 2013-04-07 & 241308439.109 & 0.000199317529083 & -16.9672587029 & 378439187.206 \\
\hline 2013-04-08 & 280111919.968 & 0.000209214019672 & -17.9793642396 & 437741879.199 \\
\hline 2013-04-09 & 201988263.429 & 0.000156175726257 & -13.1195924886 & 282584675.128 \\
\hline 2013-04-10 & 181147956.533 & 0.000200223115362 & -17.0477941637 & 259133440.218 \\
\hline 2013-04-11 & 228846926.496 & 0.000206978315709 & -18.8460886402 & 338431888.439 \\
\hline 2013-04-12 & 183631089.844 & 0.000153283558203 & -13.226675174 & 272877803.21 \\
\hline 2013-04-13 & 223513894.045 & 0.000185040047855 & -15.4004918451 & 328717289.549 \\
\hline 2013-04-14 & 199272578.736 & 0.000279851195086 & -27.1229057226 & 318094162.339 \\
\hline 2013-04-15 & 237825410.444 & 0.00010536947044 & -9.49476557929 & 353051123.926 \\
\hline 2013-04-16 & 275956307.198 & 0.000300567567101 & -23.9183353439 & 434779360.181 \\
\hline 2013-04-17 & 162262731.983 & 0.000262094428674 & -22.3945772632 & 272763175.919 \\
\hline 2013-04-18 & 82974586.1468 & 0.000610602786755 & -46.5958976279 & 185410192.143 \\
\hline 2013-04-19 & 88507472.6693 & 0.000259954512805 & -21.6919376495 & 143754056.01 \\
\hline 2013-04-20 & 68031395.0028 & 0.000449484526955 & -38.3766131975 & 119230454.464 \\
\hline 2013-04-21 & 292556220.931 & 0.000199286765133 & -15.8844557948 & 440295202.466 \\
\hline 2013-04-22 & 436323704.056 & 0.000253625683664 & -19.6109292178 & 670747233.536 \\
\hline $2013-04-23$ & 341478481.841 & 0.000224876807177 & -19.0903094313 & 517788768.446 \\
\hline 2013-04-24 & 407017229.474 & 0.000487594856181 & -40.9747483446 & 653016436.865 \\
\hline 2013-04-25 & 368817155.294 & 0.000162747488109 & -13.0976538218 & 546387196.913 \\
\hline 2013-04-26 & 149721272.911 & 0.000203000520319 & -14.0650317208 & 227118473.008 \\
\hline 2013-04-27 & 136925775.74 & 0.000231690353715 & -21.1078296939 & 210681864.227 \\
\hline 2013-04-28 & 200772495.141 & 0.000157057847042 & -13.646482707 & 291386102.455 \\
\hline 2013-04-29 & 298588454.619 & 0.000193175186475 & -16.3641258221 & 440534263.922 \\
\hline 2013-04-30 & 321053687.393 & $9.13903026692 \times 10^{-5}$ & -8.74143108092 & 445375723.086 \\
\hline 2013-05-01 & 125985285.773 & 0.000423966625778 & -34.2688922351 & 207432107.013 \\
\hline 2013-05-02 & 231487402.046 & 0.000539065575467 & -42.2833148055 & 369926688.758 \\
\hline 2013-05-03 & 203776163.79 & 0.0003437601979 & -27.2333299684 & 317651818.018 \\
\hline 2013-05-04 & 208338967.959 & 0.000346456469493 & -27.6854907624 & 325702553.336 \\
\hline 2013-05-05 & 207789963.508 & 0.000841796072708 & -67.6622303188 & 351993627.965 \\
\hline 2013-05-06 & 347418417.851 & 0.000448524359662 & -34.7780924713 & 554135086.863 \\
\hline 2013-05-07 & 299783172.592 & 0.000235981220195 & -17.9925942326 & 457931647.005 \\
\hline 2013-05-08 & 338853590.457 & 0.000222740166646 & -17.7969628434 & 515122066.518 \\
\hline 2013-05-09 & 138350731.516 & 0.000514433319282 & -39.0494638988 & 242861950.818 \\
\hline 2013-05-10 & 128460991.586 & 0.000542872119089 & -43.0392477758 & 212376408.167 \\
\hline 2013-05-11 & 197357722.636 & 0.000336170352883 & -27.1769290538 & 308896495.572 \\
\hline 2013-05-12 & 123438090.825 & 0.000551986537608 & -44.7389812631 & 216939776.454 \\
\hline 2013-05-13 & 173262903.075 & 0.000156157996316 & -13.6719350276 & 279915831.861 \\
\hline 2013-05-14 & 143307785.834 & 0.000341916985123 & -28.5463023673 & 262248737.61 \\
\hline 2013-05-15 & 171687143.506 & 0.000204960171235 & -16.8430743062 & 288242524.489 \\
\hline $2013-05-16$ & 201124120.263 & 0.000199727851722 & -16.4635685193 & 300436734.559 \\
\hline 2013-05-17 & 216048762.633 & 0.000106256317825 & -10.1785101296 & 321330376.197 \\
\hline
\end{tabular}


Table A1. Continued.

\begin{tabular}{|c|c|c|c|c|}
\hline $\begin{array}{l}\text { Date } \\
\text { (yyyy-mm-dd) }\end{array}$ & $a_{4}$ & $b_{4}$ & $c_{4}$ & $d_{4}$ \\
\hline 2013-05-18 & 127019310.246 & 0.000251878447586 & -22.4725980735 & 225359020.405 \\
\hline 2013-05-19 & 216139229.118 & 0.00021017737448 & -18.8082043681 & 347954786.732 \\
\hline 2013-05-20 & 142802725.584 & 0.00022408357457 & -18.9053267444 & 250315544.354 \\
\hline 2013-05-21 & 198870491.145 & 0.000117988992593 & -10.139042474 & 307531288.823 \\
\hline 2013-05-22 & 119432620.247 & $2.43039229589 \times 10^{-5}$ & -2.45632747881 & 157922601.653 \\
\hline $2013-05-23$ & 40255497.7353 & 0.000240171209101 & -20.0498375634 & 122178037.277 \\
\hline 2013-05-24 & 84013680.5912 & 0.000185305147735 & -15.5745760304 & 167222406.923 \\
\hline $2013-05-25$ & 139565588.11 & $7.67575081862 \times 10^{-5}$ & -7.44485213716 & 214762700.992 \\
\hline 2013-05-26 & 45132682.539 & 0.000361420216266 & -33.2187435764 & 91005818.8736 \\
\hline 2013-05-27 & 125197132.219 & 0.000124622035228 & -10.5772038594 & 199654328.249 \\
\hline $2013-05-28$ & 291094314.932 & $8.9376960719 \times 10^{-5}$ & -7.48575179534 & 386048772.609 \\
\hline 2013-05-29 & 290645572.411 & 0.000151162246919 & -12.2349270666 & 420301468.84 \\
\hline 2013-05-30 & 211052359.052 & 0.000220307547106 & -17.7401273148 & 355841319.637 \\
\hline 2013-05-31 & 135399096.842 & 0.000149711023647 & -11.6821562186 & 240861848.761 \\
\hline 2013-06-01 & 363627422.118 & $3.56015208817 \times 10^{-5}$ & -3.90250699652 & 473751252.603 \\
\hline 2013-06-02 & 17968652.1809 & 0.000996972925851 & -90.3011578173 & 144213180.306 \\
\hline 2013-06-03 & 34016040.9651 & 0.000659872472514 & -58.6294118973 & 162640835.637 \\
\hline 2013-06-04 & 107395285.649 & $8.78086171989 \times 10^{-5}$ & -7.49763902659 & 234434320.597 \\
\hline 2013-06-05 & 97909831.7666 & 0.000120067468126 & -9.79807570646 & 221959838.278 \\
\hline 2013-06-06 & 101756470.014 & 0.000456646803813 & -35.3885995398 & 243262397.72 \\
\hline 2013-06-07 & 161546476.68 & 0.00045407580782 & -34.799243064 & 334220452.75 \\
\hline 2013-06-08 & 203720180.213 & 0.000482356961371 & -37.0202588174 & 405209487.11 \\
\hline 2013-06-09 & 158442495.012 & 0.000269794457705 & -20.8081300188 & 314318566.708 \\
\hline 2013-06-10 & 141865122.829 & 0.000156947950278 & -13.0695209013 & 263075585.99 \\
\hline 2013-06-11 & 235733177.228 & 0.000230751828926 & -18.1591128028 & 410288514.094 \\
\hline 2013-06-12 & 415210885.836 & 0.000306663251406 & -24.3201029806 & 674658738.154 \\
\hline 2013-06-13 & 147073267.639 & 0.000309682098903 & -25.9637042653 & 288869265.912 \\
\hline 2013-06-14 & 120316710.214 & 0.00156899264184 & -128.236691148 & 269620027.277 \\
\hline 2013-06-15 & 150145578.989 & 0.00201136712971 & -155.146937742 & 320889638.795 \\
\hline 2013-06-16 & 102540538.867 & 0.000827094676632 & -67.9962750683 & 224807397.25 \\
\hline All Data & 199788909.439 & 0.000182424683277 & -14.8932330043 & 328676886.493 \\
\hline
\end{tabular}

Table A2. Normalized root mean square error (nRMSE), mean surface level pressure (MSLP), mean surface level temperature (MSLT), and mean integrated specific humidity (MISH).

\begin{tabular}{lrrrr}
\hline $\begin{array}{l}\text { Date } \\
\text { (yyyy-mm-dd) }\end{array}$ & nRMSE & MSLP (hPa) & MSLT (K) & MISH $\left(\mathrm{kg} \mathrm{kg}^{-1}\right)$ \\
\hline $2013-03-26$ & 0.058375 & 994.94 & 269.19 & 0.036122 \\
$2013-03-27$ & 0.017049 & 993.75 & 269.51 & 0.035218 \\
$2013-03-28$ & 0.031950 & 992.39 & 271.32 & 0.042123 \\
$2013-03-29$ & 0.042817 & 987.85 & 272.93 & 0.055698 \\
$2013-03-30$ & 0.041072 & 985.12 & 272.85 & 0.049807 \\
$2013-03-31$ & 0.026466 & 988.42 & 272.43 & 0.048879 \\
$2013-04-01$ & 0.012706 & 989.60 & 272.20 & 0.042296 \\
$2013-04-02$ & 0.015847 & 990.95 & 272.05 & 0.036133 \\
$2013-04-03$ & 0.022428 & 995.81 & 272.55 & 0.040998 \\
$2013-04-04$ & 0.029187 & 994.44 & 272.86 & 0.048369 \\
$2013-04-05$ & 0.041894 & 989.87 & 273.76 & 0.056840 \\
$2013-04-06$ & 0.028730 & 993.01 & 274.46 & 0.057399 \\
\hline
\end{tabular}


Table A2. Continued.

\begin{tabular}{|c|c|c|c|c|}
\hline $\begin{array}{l}\text { Date } \\
\text { (yyyy-mm-dd) }\end{array}$ & nRMSE & MSLP (hPa) & MSLT (K) & MISH $\left(\mathrm{kg} \mathrm{kg}^{-1}\right)$ \\
\hline 2013-04-07 & 0.042814 & 999.94 & 274.21 & 0.048450 \\
\hline 2013-04-08 & 0.026501 & 993.42 & 274.33 & 0.045672 \\
\hline 2013-04-09 & 0.027307 & 985.84 & 275.56 & 0.057698 \\
\hline 2013-04-10 & 0.076350 & 983.25 & 277.05 & 0.082018 \\
\hline 2013-04-11 & 0.035495 & 985.89 & 278.18 & 0.088811 \\
\hline 2013-04-12 & 0.034073 & 979.79 & 280.71 & 0.111517 \\
\hline 2013-04-13 & 0.031444 & 986.42 & 279.62 & 0.090808 \\
\hline 2013-04-14 & 0.037386 & 1001.00 & 279.63 & 0.096504 \\
\hline 2013-04-15 & 0.047865 & 1001.01 & 282.66 & 0.108553 \\
\hline 2013-04-16 & 0.034297 & 998.47 & 283.05 & 0.105820 \\
\hline 2013-04-17 & 0.048725 & 999.54 & 284.12 & 0.112909 \\
\hline 2013-04-18 & 0.088579 & 994.27 & 285.96 & 0.129610 \\
\hline 2013-04-19 & 0.056774 & 996.16 & 283.23 & 0.087532 \\
\hline 2013-04-20 & 0.079616 & 1004.96 & 279.29 & 0.068958 \\
\hline 2013-04-21 & 0.111945 & 1004.65 & 278.71 & 0.065744 \\
\hline 2013-04-22 & 0.055604 & 994.76 & 280.78 & 0.084171 \\
\hline 2013-04-23 & 0.030981 & 994.66 & 281.98 & 0.089663 \\
\hline 2013-04-24 & 0.015152 & 1002.46 & 281.75 & 0.091881 \\
\hline 2013-04-25 & 0.075156 & 1002.65 & 284.35 & 0.121349 \\
\hline 2013-04-26 & 0.121841 & 995.45 & 285.82 & 0.119089 \\
\hline 2013-04-27 & 0.069493 & 984.92 & 281.90 & 0.115787 \\
\hline 2013-04-28 & 0.088411 & 990.59 & 279.10 & 0.086938 \\
\hline 2013-04-29 & 0.019399 & 993.20 & 280.35 & 0.088360 \\
\hline 2013-04-30 & 0.038301 & 998.84 & 280.66 & 0.081556 \\
\hline 2013-05-01 & 0.089889 & 1002.53 & 280.47 & 0.085800 \\
\hline 2013-05-02 & 0.049596 & 999.81 & 282.07 & 0.106277 \\
\hline 2013-05-03 & 0.046556 & 997.79 & 282.30 & 0.103677 \\
\hline 2013-05-04 & 0.036288 & 994.96 & 282.31 & 0.095752 \\
\hline 2013-05-05 & 0.086737 & 999.15 & 283.10 & 0.100445 \\
\hline 2013-05-06 & 0.056681 & 1002.02 & 283.96 & 0.100265 \\
\hline 2013-05-07 & 0.024180 & 997.57 & 285.96 & 0.130177 \\
\hline 2013-05-08 & 0.052651 & 993.21 & 286.40 & 0.158999 \\
\hline 2013-05-09 & 0.089977 & 991.31 & 287.25 & 0.150291 \\
\hline 2013-05-10 & 0.106178 & 990.67 & 285.82 & 0.131964 \\
\hline 2013-05-11 & 0.030124 & 994.27 & 283.82 & 0.112145 \\
\hline 2013-05-12 & 0.067284 & 990.95 & 282.81 & 0.109726 \\
\hline 2013-05-13 & 0.035593 & 993.67 & 281.24 & 0.098355 \\
\hline 2013-05-14 & 0.037253 & 989.83 & 282.00 & 0.100587 \\
\hline 2013-05-15 & 0.042805 & 985.28 & 283.20 & 0.113195 \\
\hline 2013-05-16 & 0.034829 & 982.21 & 285.09 & 0.121981 \\
\hline 2013-05-17 & 0.040659 & 978.31 & 286.23 & 0.148483 \\
\hline 2013-05-18 & 0.026654 & 982.87 & 285.79 & 0.158700 \\
\hline 2013-05-19 & 0.031035 & 988.83 & 284.13 & 0.124771 \\
\hline $2013-05-20$ & 0.023767 & 987.02 & 284.80 & 0.141561 \\
\hline $2013-05-21$ & 0.034408 & 989.34 & 283.91 & 0.125855 \\
\hline $2013-05-22$ & 0.050486 & 986.75 & 283.17 & 0.121123 \\
\hline $2013-05-23$ & 0.083085 & 988.22 & 279.80 & 0.075196 \\
\hline 2013-05-24 & 0.080767 & 987.04 & 279.35 & 0.074817 \\
\hline $2013-05-25$ & 0.025863 & 990.34 & 281.01 & 0.094807 \\
\hline $2013-05-26$ & 0.031988 & 988.12 & 281.64 & 0.118393 \\
\hline $2013-05-27$ & 0.046164 & 985.93 & 281.49 & 0.107848 \\
\hline $2013-05-28$ & 0.046754 & 986.86 & 283.02 & 0.111575 \\
\hline 2013-05-29 & 0.023271 & 980.41 & 283.99 & 0.126150 \\
\hline 2013-05-30 & 0.032076 & 983.78 & 283.96 & 0.132437 \\
\hline
\end{tabular}


Table A2. Continued.

\begin{tabular}{lrrrr}
\hline $\begin{array}{l}\text { Date } \\
\text { (yyyy-mm-dd) }\end{array}$ & nRMSE & MSLP (hPa) & MSLT (K) & MISH $\left(\mathrm{kg} \mathrm{kg}^{-1}\right)$ \\
\hline $2013-05-31$ & 0.029660 & 983.61 & 284.88 & 0.149310 \\
$2013-06-01$ & 0.028816 & 987.35 & 284.71 & 0.144646 \\
$2013-06-02$ & 0.172472 & 992.77 & 283.76 & 0.130239 \\
$2013-06-03$ & 0.193028 & 1000.69 & 282.29 & 0.105592 \\
$2013-06-04$ & 0.042859 & 1000.92 & 282.77 & 0.109886 \\
$2013-06-05$ & 0.035022 & 999.00 & 284.02 & 0.102547 \\
$2013-06-06$ & 0.089583 & 999.76 & 284.51 & 0.108954 \\
$2013-06-07$ & 0.114967 & 1000.78 & 286.25 & 0.124497 \\
$2013-06-08$ & 0.095570 & 998.80 & 286.87 & 0.130221 \\
$2013-06-09$ & 0.120264 & 993.08 & 286.41 & 0.131837 \\
$2013-06-10$ & 0.033598 & 989.03 & 285.82 & 0.131744 \\
$2013-06-11$ & 0.069040 & 992.94 & 285.16 & 0.111053 \\
$2013-06-12$ & 0.037044 & 996.85 & 286.46 & 0.122328 \\
$2013-06-13$ & 0.046920 & 995.83 & 289.15 & 0.174709 \\
$2013-06-14$ & 0.129532 & 993.20 & 287.72 & 0.155478 \\
$2013-06-15$ & 0.157566 & 995.72 & 286.45 & 0.115220 \\
$2013-06-16$ & 0.084010 & 992.86 & 287.41 & 0.123394 \\
\hline All Data & 0.055488 & 992.65 & 281.37 & 0.100991 \\
\hline
\end{tabular}




\section{The Supplement related to this article is available online at doi:10.5194/acp-16-12059-2016-supplement.}

Author contributions. Christa Engler, working with Ina Tegen, ran the COSMO-MUSCAT model, and performed the aerosol evaluation. Luke B. Hande, working with Corinna Hoose, developed the CCN parameterization. Luke B. Hande prepared the manuscript with contributions from all co-authors.

Acknowledgements. This work was funded by the Federal Ministry of Education and Research in Germany (BMBF) through the research programme "High Definition Clouds and Precipitation for Climate Prediction - HD $(\mathrm{CP})^{2}$ " (FKZ: 01LK1204B). The authors wish to thank Geralad Spindler and Wolfgang Birmili for providing data used in the evaluation. An electronic version of the parameterization parameters is available as a supplement to this manuscript.

The article-processing charges for this open-access

publication were covered by a Research

Centre of the Helmholtz Association.

Edited by: H. Russchenberg

Reviewed by: two anonymous referees

\section{References}

Abdul-Razzak, H. and Ghan, S. J.: A parameterization of aerosol activation: 2. Multiple aerosol types, J. Geophys. Res.-Atmos., 105, 6837-6844, 2000.

Abdul-Razzak, H. and Ghan, S. J.: A parameterization of aerosol activation 3. Sectional representation, J. Geophys. Res.-Atmos., 107, AAC 1-1-AAC 1-6, doi:10.1029/2001JD000483, 2002.

Abdul-Razzak, H., Ghan, S. J., and Rivera-Carpio, C.: A parameterization of aerosol activation: 1. Single aerosol type, J. Geophys. Res.-Atmos., 103, 6123-6131, 1998.

Bellouin, N., Mann, G. W., Woodhouse, M. T., Johnson, C., Carslaw, K. S., and Dalvi, M.: Impact of the modal aerosol scheme GLOMAP-mode on aerosol forcing in the Hadley Centre Global Environmental Model, Atmos. Chem. Phys., 13, 30273044, doi:10.5194/acp-13-3027-2013, 2013.

Birmili, W., Stratmann, F., and Wiedensohler, A.: Design of a DMA-based size spectrometer for a large particle size range and stable operation, J. Aerosol Sci., 30, 549-553, 1999.

Birmili, W., Weinhold, K., Rasch, F., Sonntag, A., Sun, J., Merkel, M., Wiedensohler, A., Bastian, S., Schladitz, A., Löschau, G., Cyrys, J., Pitz, M., Gu, J., Kusch, T., Flentje, H., Quass, U., Kaminski, H., Kuhlbusch, T. A. J., Meinhardt, F., Schwerin, A., Bath, O., Ries, L., Wirtz, K., and Fiebig, M.: Long-term observations of tropospheric particle number size distributions and equivalent black carbon mass concentrations in the German U1trafine Aerosol Network (GUAN), Earth Syst. Sci. Data, 8, 355382, doi:10.5194/essd-8-355-2016, 2016.
Boucher, O., Randall, D., Artaxo, P., Bretherton, C., Feingold, G., Forster, P., Kerminen, V.-M., Kondo, Y., Liao, H., Lohmann, U., Rasch, P., Satheesh, S., Sherwood, S., Stevens, B., and Zhang, X.: Clouds and Aerosols. In: Climate Change 2013: The Physical Science Basis. Contribution of Working Group I to the Fifth Assessment Report of the Intergovernmental Panel on Climate Change, Intergovernmental Panel on Climate Change, Working Group I Contribution to the IPCC Fifth Assessment Report (AR5)(Cambridge Univ Press, New York), 2013.

Dipankar, A., Stevens, B., Heinze, R., Moseley, C., Zängl, G., Giorgetta, M., and Brdar, S.: Large eddy simulation using the general circulation model ICON, Journal of Advances in Modeling Earth Systems, 7, 963-986, doi:10.1002/2015MS000431, 2015.

Dusek, U., Frank, G. P., Hildebrandt, L., Curtius, J., Schneider, J., Walter, S., Chand, D., Drewnick, F., Hings, S., Jung, D., Borrmann, S., and Andreae, M. O.: Size matters more than chemistry for cloud-nucleating ability of aerosol particles, Science, 312, 1375-1378, 2006.

Engler, C., Rose, D., Wehner, B., Wiedensohler, A., Brüggemann, E., Gnauk, T., Spindler, G., Tuch, T., and Birmili, W.: Size distributions of non-volatile particle residuals $\left(D_{p}<800 \mathrm{~nm}\right)$ at a rural site in Germany and relation to air mass origin, Atmos. Chem. Phys., 7, 5785-5802, doi:10.5194/acp-7-5785-2007, 2007.

Ervens, B., Cubison, M., Andrews, E., Feingold, G., Ogren, J. A., Jimenez, J. L., DeCarlo, P., and Nenes, A.: Prediction of cloud condensation nucleus number concentration using measurements of aerosol size distributions and composition and light scattering enhancement due to humidity, J. Geophys. Res.-Atmos., 112, D10S32, doi:10.1029/2006JD007426, 2007.

Ervens, B., Cubison, M. J., Andrews, E., Feingold, G., Ogren, J. A., Jimenez, J. L., Quinn, P. K., Bates, T. S., Wang, J., Zhang, Q., Coe, H., Flynn, M., and Allan, J. D.: CCN predictions using simplified assumptions of organic aerosol composition and mixing state: a synthesis from six different locations, Atmos. Chem. Phys., 10, 4795-4807, doi:10.5194/acp-10-4795-2010, 2010.

Feingold, G.: Modeling of the first indirect effect: Analysis of measurement requirements, Geophys. Res. Lett., 30, 1997, doi:10.1029/2003GL017967, 2003.

Fountoukis, C. and Nenes, A.: Continued development of a cloud droplet formation parameterization for global climate models, J. Geophys. Res.-Atmos., 110, D11212, doi:10.1029/2004JD005591, 2005.

Ghan, S., Laulainen, N., Easter, R., Wagener, R., Nemesure, S., Chapman, E., Zhang, Y., and Leung, R.: Evaluation of aerosol direct radiative forcing in MIRAGE, J. Geophys. Res.-Atmos., 106, 5295-5316, 2001.

Gong, S.: A parameterization of sea-salt aerosol source function for sub-and super-micron particles, Global Biogeochem. Cy., 17, 1097, doi:10.1029/2003GB002079, 2003.

Hande, L. B., Engler, C., Hoose, C., and Tegen, I.: Seasonal variability of Saharan desert dust and ice nucleating particles over Europe, Atmos. Chem. Phys., 15, 4389-4397, doi:10.5194/acp15-4389-2015, 2015.

Heinold, B., Tegen, I., Schepanski, K., Tesche, M., Esselborn, M., Freudenthaler, V., Gross, S., Kandler, K., Knippertz, P., Müller, D., Schladitz, A., Toledano, C., Weinzierl, B., Ansmann, A., Althausen, D., Muller, T., and Petzold, A.: Regional modelling of Saharan dust and biomass-burning smoke, Tellus B, 63, 781-799, 2011. 
Hudson, J. G.: Variability of the relationship between particle size and cloud-nucleating ability, Geophys. Res. Lett., 34, L08801, doi:10.1029/2006GL028850, 2007.

Khvorostyanov, V. I. and Curry, J. A.: A simple analytical model of aerosol properties with account for hygroscopic growth: 1. Equilibrium size spectra and cloud condensation nuclei activity spectra, J. Geophys. Res.-Atmos., 104, 2175-2184, 1999.

Liu, X., Easter, R. C., Ghan, S. J., Zaveri, R., Rasch, P., Shi, X., Lamarque, J.-F., Gettelman, A., Morrison, H., Vitt, F., Conley, A., Park, S., Neale, R., Hannay, C., Ekman, A. M. L., Hess, P., Mahowald, N., Collins, W., Iacono, M. J., Bretherton, C. S., Flanner, M. G., and Mitchell, D.: Toward a minimal representation of aerosols in climate models: description and evaluation in the Community Atmosphere Model CAM5, Geosci. Model Dev., 5, 709-739, doi:10.5194/gmd-5-709-2012, 2012.

Mann, G. W., Carslaw, K. S., Ridley, D. A., Spracklen, D. V., Pringle, K. J., Merikanto, J., Korhonen, H., Schwarz, J. P., Lee, L. A., Manktelow, P. T., Woodhouse, M. T., Schmidt, A., Breider, T. J., Emmerson, K. M., Reddington, C. L., Chipperfield, M. P., and Pickering, S. J.: Intercomparison of modal and sectional aerosol microphysics representations within the same 3-D global chemical transport model, Atmos. Chem. Phys., 12, 4449-4476, doi:10.5194/acp-12-4449-2012, 2012.

Morrison, H., Curry, J., and Khvorostyanov, V.: A new doublemoment microphysics parameterization for application in cloud and climate models. Part I: Description, J. Atmos. Sci., 62, 16651677, 2005.

Nenes, A. and Seinfeld, J. H.: Parameterization of cloud droplet formation in global climate models, J. Geophys. Res.-Atmos., 108, 4415, doi:10.1029/2002JD002911, 2003.

Petters, M. D. and Kreidenweis, S. M.: A single parameter representation of hygroscopic growth and cloud condensation nucleus activity, Atmos. Chem. Phys., 7, 1961-1971, doi:10.5194/acp-71961-2007, 2007.

Pierce, J. R. and Adams, P. J.: Uncertainty in global CCN concentrations from uncertain aerosol nucleation and primary emission rates, Atmos. Chem. Phys., 9, 1339-1356, doi:10.5194/acp-91339-2009, 2009.

Renner, E. and Wolke, R.: Modelling the formation and atmospheric transport of secondary inorganic aerosols with special attention to regions with high ammonia emissions, Atmos. Environ., 44, 1904-1912, 2010.

Rissler, J., Swietlicki, E., Zhou, J., Roberts, G., Andreae, M. O., Gatti, L. V., and Artaxo, P.: Physical properties of the submicrometer aerosol over the Amazon rain forest during the wetto-dry season transition - comparison of modeled and measured CCN concentrations, Atmos. Chem. Phys., 4, 2119-2143, doi:10.5194/acp-4-2119-2004, 2004.
Segal, Y. and Khain, A.: Dependence of droplet concentration on aerosol conditions in different cloud types: Application to droplet concentration parameterization of aerosol conditions, J. Geophys. Res.-Atmos., 111, D15204, doi:10.1029/2005JD006561, 2006.

Shipway, B. and Abel, S.: Analytical estimation of cloud droplet nucleation based on an underlying aerosol population, Atmos. Res., 96, 344-355, 2010.

Spindler, G., Grüner, A., Müller, K., Schlimper, S., and Herrmann, H.: Long-term size-segregated particle $\left(\mathrm{PM}_{10}, \mathrm{PM}_{2.5}, \mathrm{PM}_{1}\right)$ characterization study at Melpitz-influence of air mass inflow, weather conditions and season, J. Atmos. Chem., 70, 165-195, 2013.

Sullivan, R. C., Moore, M. J. K., Petters, M. D., Kreidenweis, S. M., Roberts, G. C., and Prather, K. A.: Effect of chemical mixing state on the hygroscopicity and cloud nucleation properties of calcium mineral dust particles, Atmos. Chem. Phys., 9, 33033316, doi:10.5194/acp-9-3303-2009, 2009.

Twomey, S.: The nuclei of natural cloud formation part II: The supersaturation in natural clouds and the variation of cloud droplet concentration, Geofisica pura e applicata, 43, 243-249, 1959.

Wang, J., Cubison, M. J., Aiken, A. C., Jimenez, J. L., and Collins, D. R.: The importance of aerosol mixing state and size-resolved composition on $\mathrm{CCN}$ concentration and the variation of the importance with atmospheric aging of aerosols, Atmos. Chem Phys., 10, 7267-7283, doi:10.5194/acp-10-7267-2010, 2010.

Wang, M. and Penner, J.: Aerosol indirect forcing in a global model with particle nucleation, Atmospheric Chemistry and Physics, 9, 239-260, 2009.

Weisenstein, D. K., Penner, J. E., Herzog, M., and Liu, X.: Global 2D intercomparison of sectional and modal aerosol modules, Atmos. Chem. Phys., 7, 2339-2355, doi:10.5194/acp-7-2339-2007, 2007.

Wolke, R., Schröder, W., Schrödner, R., and Renner, E.: Influence of grid resolution and meteorological forcing on simulated European air quality: a sensitivity study with the modeling system COSMO-MUSCAT, Atmos. Environ., 53, 110-130, 2012.

Zhao, D. F., Buchholz, A., Kortner, B., Schlag, P., Rubach, F., Fuchs, H., Kiendler-Scharr, A., Tillmann, R., Wahner, A., Watne, Å. K., Hallquist, M., Flores, J. M., Rudich, Y., Kristensen, K., Hansen, A. M. K., Glasius, M., Kourtchev, I., Kalberer, M., and Mentel, Th. F.: Cloud condensation nuclei activity, droplet growth kinetics, and hygroscopicity of biogenic and anthropogenic secondary organic aerosol (SOA), Atmos. Chem. Phys., 16, 1105-1121, doi:10.5194/acp-16-1105-2016, 2016. 